\title{
Biomass-waste derived graphene quantum dots and their applications
}

\author{
Aumber Abbas ${ }^{\mathrm{a}}$, Lim Tuti Mariana*b, and Anh N. Phan*a \\ ${ }^{a}$ School of Engineering, Newcastle University, Newcastle upon Tyne, NE1 7RU, United Kingdom. \\ ${ }^{b}$ School of Civil and Environmental Engineering, Nanyang Technological University, 639798, Singapore.
}

\begin{abstract}
Energy crisis, environmental deterioration and increasing customer needs have compelled scientists to search facile, low cast, and green routes for the production of novel advanced materials from renewable resources. Among various materials explored, carbon based nanomaterials, especially graphene and graphene quantum dots (GQDs), have attracted extensive attention recently owning to their intriguing properties, such as high conductivity, extensive surface area, good biocompatibility, low toxicity, and long life. This review focuses on the conversion of biomass-waste into GQDs through a number of facile, low cost and scalable routes. Factors affecting the physical and chemical properties of GQDs for numerous promising applications have also been discussed. GQDs have shown promising applications in the field of catalysis, carbon fixation, fuel cells, bio-imaging, drug delivery, and gas sensors. Interestingly, the recent and novel applications of GQDs in the conversion and storage of energy has been discussed here. Finally, the remaining challenges, future perspectives and possible research directions in the field are presented. ${ }^{1}$
\end{abstract}

\section{Contents}

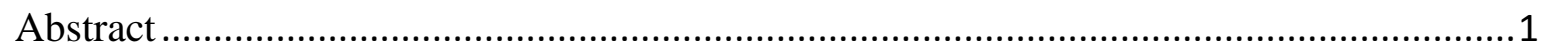

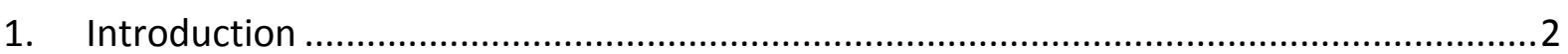

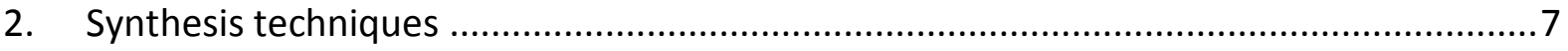

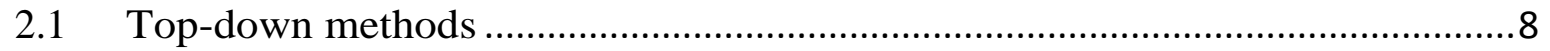

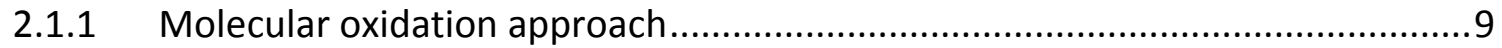

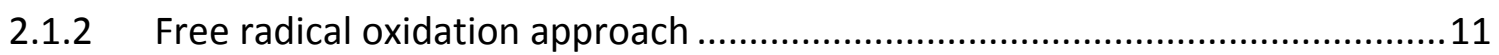

*Corresponding Authors: tmlim@ntu.edu.sg (Lim Tuti Mariana), anh.phan@ncl.ac.uk (Anh N Phan) 


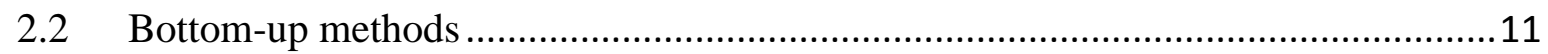

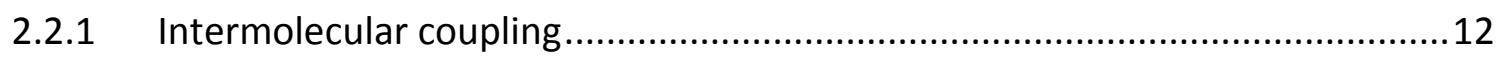

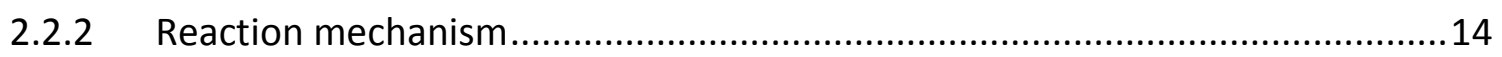

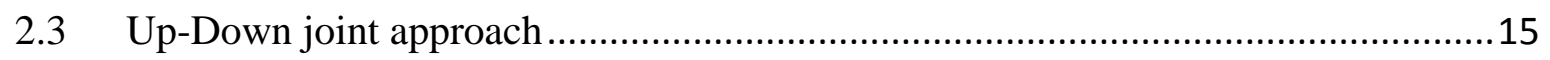

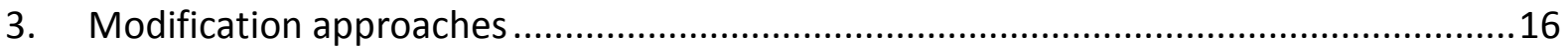

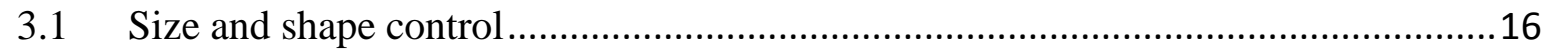

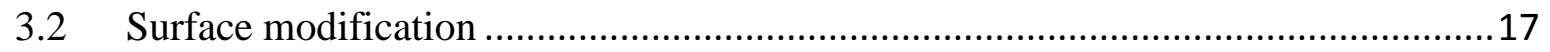

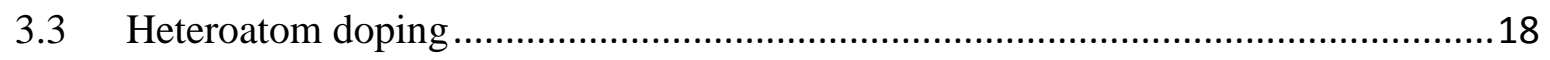

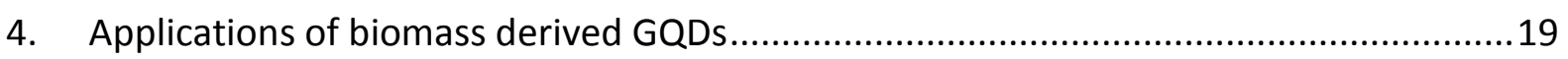

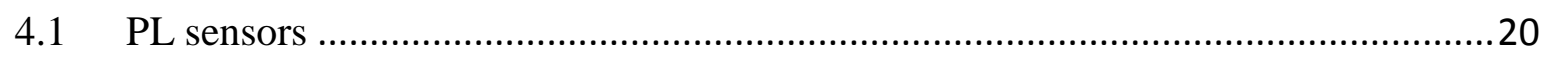

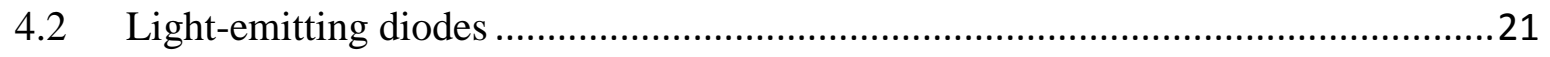

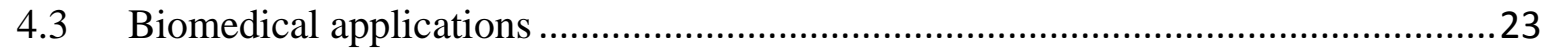

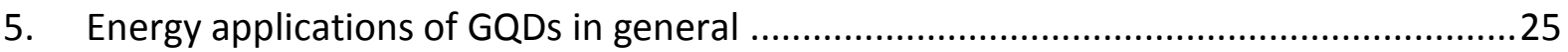

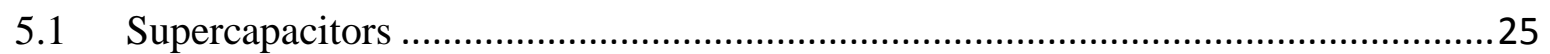

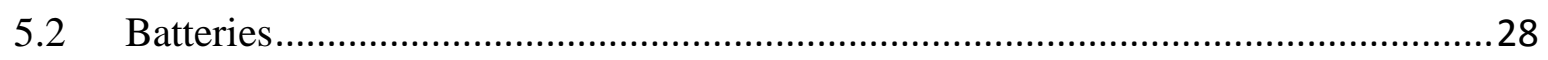

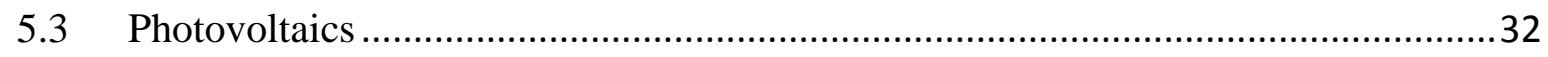

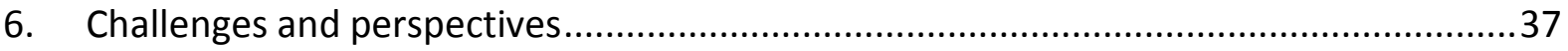

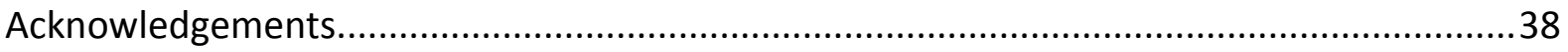

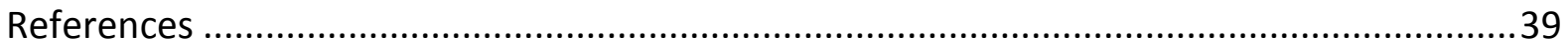

\section{Introduction}

Energy shortage, limited availability, and overconsumption of non-renewable resources coupled with rapid deterioration of the natural environment are the major problems of the modern world [1-3]. These challenges of global warming and environmental pollution have driven research into clean, sustainable, renewable, and environmentally friendly resources to produce novel functional materials [4]. Among advanced functional materials investigated, carbon-based materials have attracted much attention in numerous potential fields due to their excellent properties, such as large surface area, tunable structure, high conductivity, low toxicity and long life [5-7]. Carbon based materials have been produced and used for over 3000 years [8]. Since the discovery of fullerenes [9] in 1980s, the material science and engineering associated with carbon materials has become an area of high interest. These carbon based materials find promising applications in the fields of carbon fixation, gas storage, adsorbents, catalyst support, carbon fuel cells, electrodes, cell biology and cosmetics [10-12]. A wide 
range of approaches such as pyrolysis, carbonization, laser ablation, high-voltage arc electricity, and hydrothermal carbonization have been reported for the synthesis of carbonaceous, amorphous, or crystalline materials with diverse shape, size, and morphology $[4,13-15]$.

Carbon-based materials are traditionally produced from non-renewable sources such as coal $[6,16]$ and petroleum coke [17]. However, increasing demand and sharp decline of nonrenewable resources requires the synthesis of carbon based materials from renewable rawmaterials. Biomass waste (agricultural residues, food waste, municipal solid waste etc.) is an environmental friendly renewable resource for preparation of high valued carbon materials due to its high carbon content (45-55 wt.\%) and abundance [18]. Its thermal treatment removes all the carbohydrates resulting in a carbon rich material, known as charcoal [18]. Although biomass waste is high in carbon content [19], only a small percentage (ca. 20-30\%) [20] from human daily activities and agriculture are recycled, composted or combusted at presented while other (ca. 70-80\%) is disposed into landfill [20]. It can be considered as a potential precursor to produce carbon based materials with new functionalities and grow a more sustainable materials industry. Recently, carbon materials derived from biowaste have revealed potential applications in hydrogen storage, biomedicine, sorption materials, and so on [21, 22]. However, more work is required for commercialization of biomass derived carbon materials for sufficient performance, activity and effectiveness.

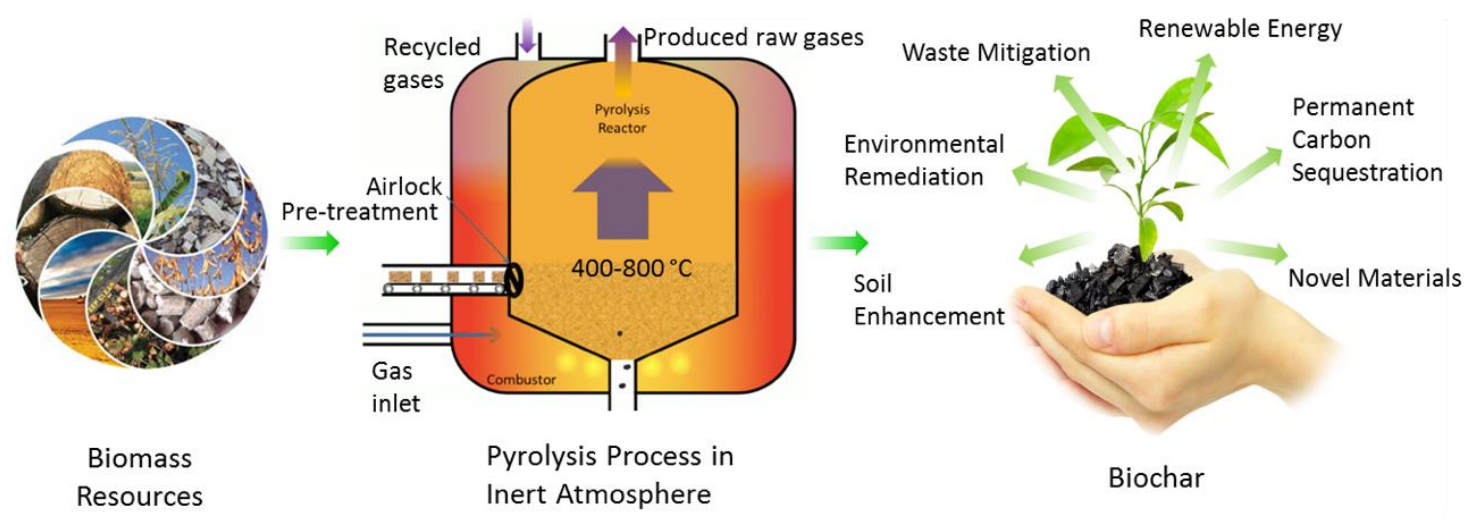

Fig. 1. Schematic representation of pyrolysis process and market benefits of the biochar obtained.

Since $20^{\text {th }}$ century, thermochemical conversion of biomass has been a topic of intensive research and several techniques, such as pyrolysis, gasification, liquefaction and hydrothermal carbonization (HTC), have been implemented to convert biomass into different products [23, 24]. Pyrolysis and HTC are the two well-known processes to acquire biochar from biomass 
[25]. Pyrolysis, which is the thermochemical decomposition of organic matter at elevated temperature $\left(450-650^{\circ} \mathrm{C}\right)$ in inert environment, is considerably flexible in terms of adjusting operating parameters (heating rate, temperature, residence time, etc.) to get desirable products [24]. Fig. 1 shows the schematic representation of pyrolysis process and its product (char) applications. Slow pyrolysis approach is usually applied for the synthesis of charcoal. The main parameters for slow pyrolysis may fluctuate from $400{ }^{\circ} \mathrm{C}$ to $800{ }^{\circ} \mathrm{C}$ temperature [26] with heating rate of $1-30{ }^{\circ} \mathrm{C} / \mathrm{min}[27,28]$ and a holding time of $1-5$ hours [29-31]. On the other hand fast pyrolysis, usually carried out at a heating rate of ca. $>100{ }^{\circ} \mathrm{C} / \mathrm{min}[31,32]$, is primarily conducted for production of liquid product [33-35].

HTC, which is the thermochemical degradation of biomass in the presence of water (water/biomass ratio may vary from 5:1 to 75:1) [36-38] at elevated temperature and pressure, is another promising techniques to convert biomass into novel carbon materials for a wide variety of potential applications [4, 39]. Based on the reaction mechanisms and experimental conditions, HTC can be classified into two major categories [4]. A high temperature HTC process is performed at high temperature $\left(400-800{ }^{\circ} \mathrm{C}\right)[40]$ and pressure to produce activated carbon materials, graphite, and carbon nanotubes [41-45]. A low temperature HTC process is conducted at low temperature $\left(200-300^{\circ} \mathrm{C}\right)$ and pressure to synthesize numerous carbonaceous materials with varied morphology, size, shape, and surface functionalities [23, 42, 46-48]. This low temperature HTC process employs several chemical transformations and is environmentally friendly [49-51]. Based on the HTC route employed, the carbonaceous materials obtained with different size, shape, morphology and properties has been implemented in the field of energy, catalysis, sensors, biology or environment [52]. Moreover, the chemical and physical properties of these carbonaceous materials can be further modified by combining them with other components, such as nanoparticles of noble metals (e.g. Au, Pt etc.) [15, 50]. 


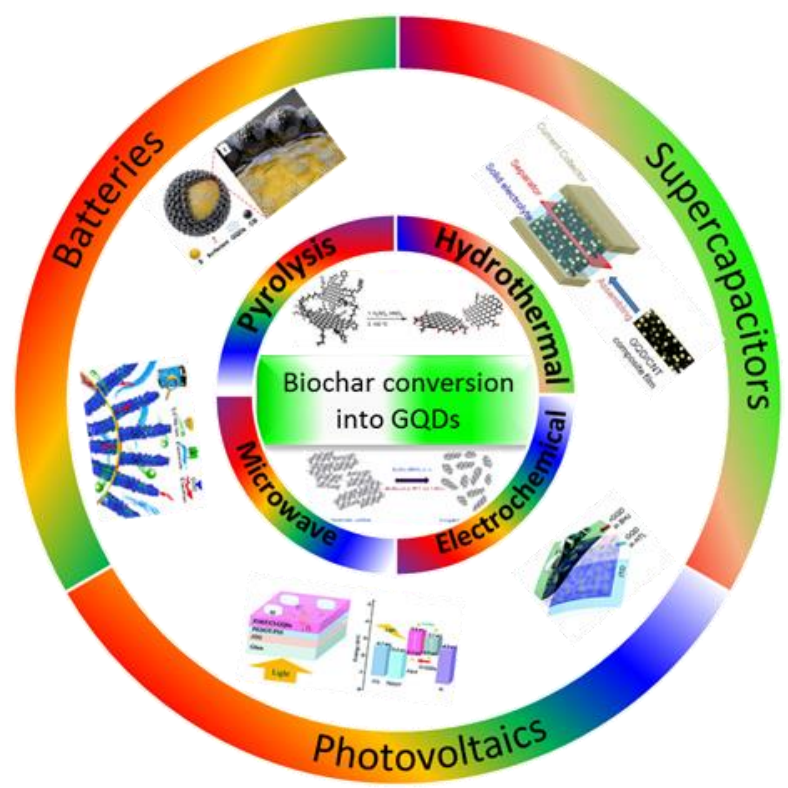

Fig. 2. Schematic illustration of the conversion of biowaste into GQDs through various approaches and their energy applications.

During the last several years, there has been a continuous eagerness to further convert carbonaceous materials into zero-dimensional (0D) GQDs [6, 53-55] and study their phenomenon of quantum confinement and edge effects $[7,56]$. Graphene is a single layer of carbon atoms arranged in a hexagonal pattern and is typically in the length of microns [57] . If we keep cutting this micrometric sheet until it reaches to less than $20 \mathrm{~nm}$ in size, the resulting product is called quantum dots [58]. Thus, GQDs are disks of graphene in the size range of 1$20 \mathrm{~nm}$. The main difference between the graphene and GQDs is the band gap. Graphene is a zero bandgap material while the GQDs show band gap due to their quantum confinement and edge effects $[59,60]$. GQDs are composed mainly of $\mathrm{sp}^{2}$ hybridized carbon and they are crystalline [60, 61]. GQDs are fluorescent due to their quantum confinement, surface defects and zigzag/armchair edges [60]. The tunable bandgap impart GQDs tunable fluorescence properties. The theoretical predictions and experimental works have indicated that the quantum confinement and edge effects are more pronounced in GQDs than other semiconductor quantum dots (SQDs). Based on this property, GQDs are anticipated to exhibit interesting phenomena which may be difficult to observe in SQDs [59, 62].

On the other hand, carbon quantum dots -also called carbon dots (C-dots)- are quasispherical carbon nanoparticles consisting of graphite and turbostratic carbon mixture in different ratios and are in the size range of 2-10 $\mathrm{nm}[63,64]$. They are composed mainly of $\mathrm{sp}^{3}$ hybridized carbon and are usually amorphous. Their XRD pattern show double character $\left(18.2^{\circ}\right.$ and $23.8^{\circ}$ ) attributed to amorphous and graphitic constituents. C-dots contain larger amount of 
oxygen with lower content of carbon as compared to GQDs [65, 66]. Due to their high oxygen content these materials are sometimes refereed as carbogenic nanodots [67]. The fluorescence in $\mathrm{C}$-dots is due to the surface defects and functionalization, which explains why they can be quenched in some medium [64].

To date the difference between GQDs and C-dots is not much clear and sometimes GQDs are considered as a type of C-dots similarly as graphene is a type of carbon. Therefore, we consider them as a family of quantum dots made of carbon. Their quantum confinement effect is still not well understood and is not completely the same as semiconductor quantum dots, such as CdS, CdSe, etc. [62].

The GQDs are strongly luminescent, biocompatible, dispersible in a number of solvents, and usually nontoxic, demonstrating a great potential for integration onto devices of bioimaging, batteries, supercapacitors, photovoltaics and light emitting diodes (Fig. 2) [7, 68-71]. A number of techniques have been developed for the synthesis of GQDs, such as hydrothermal, electrochemical, microwave, electron beam lithography or thermal treatment [62]. However, most of these methods comprise expensive non-renewable raw materials, such as CNTs, graphene, graphene oxide and its derivatives. These graphene-based precursors are very expensive and if prepared from bulk graphite, require a series of processes that could take several days and involve a lot of toxic chemicals. In addition, the strong and well-ordered structure of graphene requires a special high pressure-high temperature equipment and strong acidic treatment for disintegration into small sized GQDs [53], leading to very low yields and limiting their scalable production. Some other carbon sources such as C60 molecules, glucose, and starch, etc. have also been used along with relatively green approaches such as electrochemical treatment, however, the yield is such a low that real world application is far from realization [53].

To this end, biomass stand out as a green, natural, inexpensive, sustainable and renewable carbon source for the scalable production of GQDs. Although there is no published literature with respect to total cost of GQDs materials, it is expected that the cost of (waste) biomass derived precursor should be much lower than any other precursor (graphite, carbon fibre, CNTs, citric acid, glucose, etc.) since biomass is abundant and cheap. Different types of biomass, such as various plant leaves, grass, rice husks, coffee grounds, and wood charcoal have been used to produce GQDs with product yield comparable to graphene based expensive precursors [55, 72-75]. Interestingly, the quantum yield of biomass derived GQDs was found 
even superior to graphene derivatives [72]. Plant leaves have been reported to produce GQDs without the use of any passivating, reducing, oxidizing agents, or organic solvents, making the green production possible [72]. This is due to various functional groups already present in the structure of biomass, which makes the disintegration easier as compared to dense well-ordered single constituent graphene or CNTs. In addition, it has been demonstrated that pyrolysis treatment of biomass can produce a very interesting and highly porous form of carbon consisting of tiny nanometre scale graphene like entities juxtaposed with each other in a disordered fashion. This form of carbon is known as turbostratic carbon [76]. The thermal treatment of this disordered carbon at a temperature as low as $90{ }^{\circ} \mathrm{C}$ can lead to the production of GQDs at large scale [74], making one step nearer to the inexpensive commercial production. On the other hand, biomass derived GQDs face the challenge of precise control over particle size and usually give a large particle size of 5-7 $\mathrm{nm}$. Since bandgap is dependent on the size of GQDs due to quantum confinement effect, hence controlling the size is critically important. Thus, more work is required in terms of controllable production of GQDs from biomass.

Recently, biomass is attracting extensive attention as a potential precursor owning to its low cost, sustainability, high carbon content, and facile conversion into GQDs. However, it faces numerous challenges at the moment which needs to be understood and tackled for the cost-effective commercial production. That is exactly why there is great need for a critical review on the use of biomass as a potential precursor for the scalable production of GQDs.

This review focuses on investigating the possibility of converting the biomass waste into innovative carbonaceous materials, GQDs, and discovering their promising applications in the field of energy conversion and storage, to achieve dual goals of solving the future energy demands and bio-waste recycle problems. The possible routes for converting biowaste into activated carbon (AC) to synthesize GQDs are discussed. Moreover, the performance of GQDs on energy storage (i.e. battery, supercapacitor) and conversion devices (i.e. photovoltaic) is also evaluated.

\section{Synthesis techniques}

There are numerous techniques available for the fabrication of GQDs from various precursors, including biomass waste. These techniques can be categorised into two major groups based on the reaction mechanism: bottom-up and top-down (Fig. 3). The bottom-up technique is associated with the synthesis of $\mathrm{sp}^{2}$ carbon domains (the 2-dimensional (2D) arrangement of carbon atoms in a pattern where the angle between two consecutive bonds is 
$120^{\circ}$ ) from organic molecules through intermolecular coupling and carbonation process, resulting in a controllable size and morphology of the products. However, these approaches are time consuming and rather complicated. The main reaction mechanism involved in the topdown methods is the oxidation process (etching or cutting) or mechanical shearing. The topdown processes consist of converting large $\mathrm{sp}^{2}$ carbon domains into smaller ones by chemical oxidation or mechanical shearing, usually resulting in GQDs with high yields [58]. These methods are simple, easy to operate and time saving, but the precursors are limited to those with large area of $\mathrm{sp}^{2}$ carbon domains, such as graphene, carbon fibre, carbon black, etc. [6, $58,77]$.

\subsection{Top-down methods}

The 3-dimensional (3D) mass materials or 2-dimensional (2D) sheets consisting of large $\mathrm{sp}^{2}$ carbon domains can be cracked down in to OD quantum dots (QDs) via oxidation process or mechanical shearing. In order to achieve these goals different preparation methods have been developed. For the oxidation of large $\mathrm{sp}^{2}$ carbon domains, electrochemical scissoring, chemical etching, hydrothermal or solvothermal cutting processes have been developed. The key mechanism of oxidation processes can be classified into molecular oxidation (mainly in the case of $\left.\mathrm{H}_{2} \mathrm{SO}_{4}, \mathrm{HNO}_{3}, \mathrm{KCLO}_{3}, \mathrm{KMnO}_{4}\right)[56,78]$ and free radical oxidation approaches (particularly in $\mathrm{H}_{2} \mathrm{O}_{2}$ oxidation and electrochemical scissoring) [79-81]. Recently, several researchers have systematically reviewed $[53,82]$ the GQDs synthesis via electrochemical scissoring [83], chemical etching [84], hydrothermal or solvothermal cutting [85], ball milling [86] and ultrasonication treatment [87]. Through the systematic studies, it has been noticed that precursor material, filling factor, heating rate, reaction time, and temperature significantly affect the shape, size distribution, morphology and surface chemistry of GQDs [62]. The synthesis of GQDs from biomass-waste via different reaction mechanisms are discussed in the following section. 


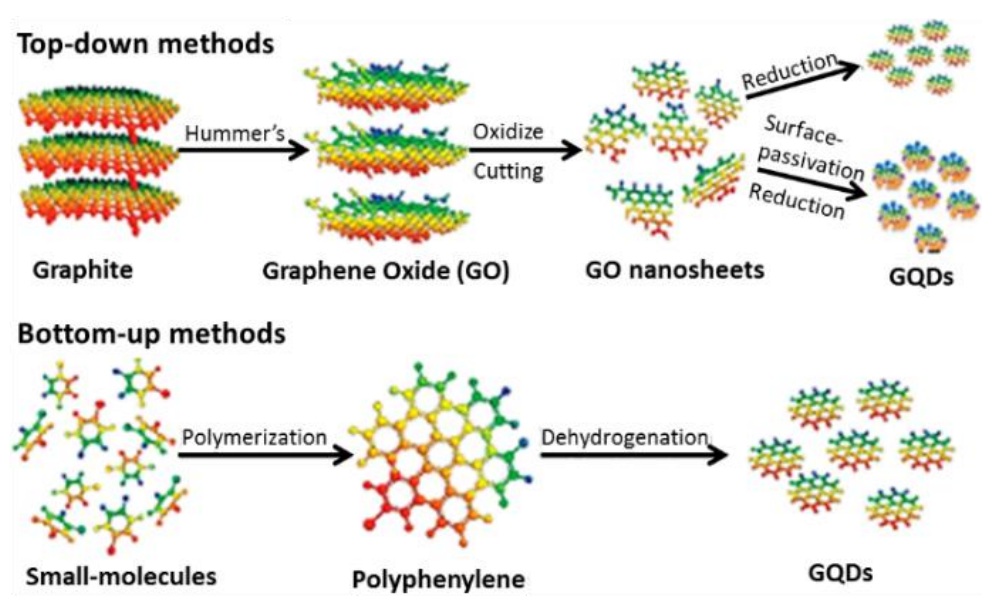

Fig. 3. Schematic demonstration of the top-down and bottom up approaches for synthesis of GQDs. Adopted with permission from ref. [7]. Copyright (2012) Royal Society of Chemistry.

\subsubsection{Molecular oxidation approach}

Molecular oxidation is a versatile approach implemented for the synthesis of GQDs with relatively high yields. Yang et al. reported on the large scale production (>100 g) of carbon based quantum dots with high yield (80\%) through molecular oxidation cutting of Chinese ink [78]. GQDs have been efficiently synthesized by the molecular oxidation of turbostratic carbon derived from biomass using strong acids [74]. An interesting carbon material is acquired by the controlled pyrolysis of the biomass at temperature below $1000{ }^{\circ} \mathrm{C}$. At this temperature, graphitization process is incomplete which results in small graphene-like entities combined in irregular style. This type of carbon is recognised as turbostartic carbon. GQDs were synthesized by refluxing the turbostratic carbon mixed with strong acids $\left(\mathrm{H}_{2} \mathrm{SO}_{4} \& \mathrm{HNO}_{3}, 3: 1\right)$ at $90{ }^{\circ} \mathrm{C}$ for several hours (Fig. 4a) [74]. This method result in the origination of oxygenated groups $(\mathrm{OH}$, $\mathrm{COOH}$, etc.) on basal plans, activating them and making them defective in structure. These activated $\mathrm{sp}^{2}$ carbon domains eventually break down into smaller pieces after long time exposure at elevated temperature, forming GQDs.

Hydrothermal treatment is another molecular oxidation technique widely implemented for the synthesis of GQDs from various precursors, especially crude biomass [73, 75]. Pan et al. first introduced facile hydrothermal route for the synthesis of GQDs with blue-luminescence [58]. Biomass derived carbonaceous material consisting of large $\mathrm{sp}^{2}$ domains are reacted with oxidizing reagents (e.g. $\mathrm{HNO}_{3}$ ) for introducing epoxy groups on basal planes. Finally the GQDs are obtained by hydrothermal cutting followed by deoxidization in alkaline media (Fig. 4b). A large scale and controllable synthesis of GQDs from rice husk was reported by Wang et al [73]. Rice husks were pyrolysed at $700{ }^{\circ} \mathrm{C}$ for $2 \mathrm{~h}$ and reacted with $\mathrm{NaOH}$ under protective 
environment at $900{ }^{\circ} \mathrm{C}$ to produce rice husk carbon (RHC). RHC was then activated with strong acids and subjected to hydrothermal treatment at $200{ }^{\circ} \mathrm{C}$ for $10 \mathrm{~h}$ to produce GQDs with a yield of $15 \%$. As prepared GQDs exhibit intense photoluminescence and high biocompatibility showing a bright promise for biomedical fields [73]. A novel and acid free hydrothermal approach was recently developed by Wang et al. for the synthesis of GQDs from coffee grounds [75]. Hydrazine hydrate was used as an activating agent instead of strong acids. The coffee grounds were mixed with hydrazine hydrate and water under mild ultrasonication. The hydrothermal treatment of the as prepared mixture at $150-200{ }^{\circ} \mathrm{C}$ for $6-10 \mathrm{~h}$ resulted in the blue luminescent GQDs. They also prepared PEI-functionalized GQDs with high band-edge luminescence for bio-imaging and sensing applications [75]. A good advancement in the hydrothermal field was made by Roy et al., who synthesized GQDs from plant leaf without the use of any oxidizing, reducing or passivating agents [72]. They prepared graphene oxide sheets by the hydrothermal treatment of Neem leaves extract at $300{ }^{\circ} \mathrm{C}$ for $2 \mathrm{~h}$, which were subsequently broken down into GQDs after $8 \mathrm{~h}$ of treatment (Fig. 4c). As obtained GQDs were highly photo-stable and suitable for white light emitting diodes [72].

(a)

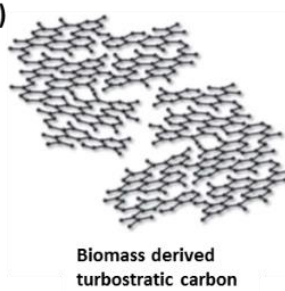

(b)

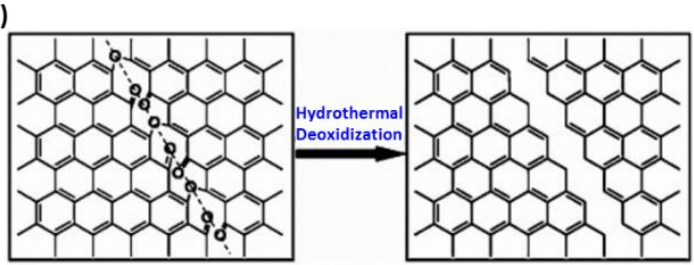

(c)

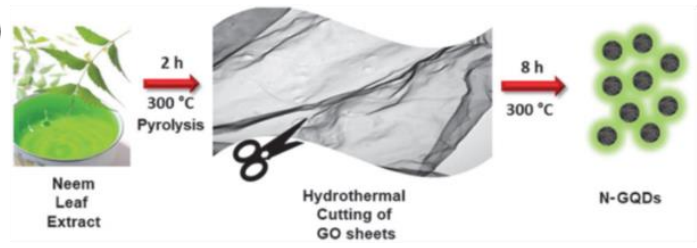

(d)

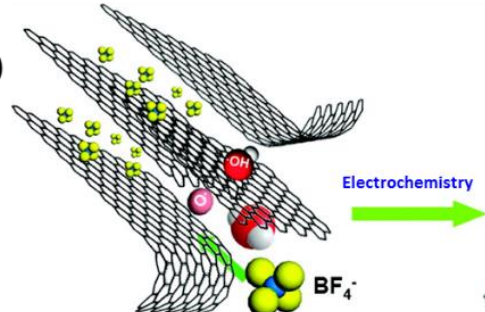

Fig. 4. Top down approaches for the synthesis of GQDs. (a) Schematic for the fabrication of GQDs by acidic oxidation of turbostratic carbon obtained from biomass. Reprinted with permission from ref. [74]. Copyright (2014) Royal Society of Chemistry. (b) Mechanism for the synthesis of GQDs by cutting the mixed epoxy chains of graphene sheets under hydrothermal treatment. Reprinted with permission from ref. [58]. Copyright (2010) Wiley Publishing Group. (c) Schematic representation of the synthesis procedure for GQDs from Neem leaf via hydrothermal route. Reprinted with permission from ref. [72]. Copyright (2014) Centre National de la Recherche Scientifique and Royal Society of Chemistry. (d) Exfoliation process representing the attack of hydroxyl and oxygen radicals on graphite edge planes, and intercalation of BF ${ }^{4-}$ anion. Reprinted with permission from ref. [88]. Copyright (2009) American Chemical Society. 


\subsubsection{Free radical oxidation approach}

Free radical oxidation is a facile, clean and efficient approach for the synthesis of GQDs without any by-products [80, 81]. This approach is different from traditional molecular oxidation approach in reaction mechanism. Molecular oxidizing and acidic intercalation destroys the perfect $\mathrm{sp}^{2}$ structure of the natural graphite resulting in the introduction of $\mathrm{sp}^{3}$ carbon and large amount of oxygen containing groups. These $\mathrm{sp}^{3}$ carbon domains are preferentially oxidized, playing a key role in the morphological trimming of graphene into GQDs. On the other hand, free radical oxidation involves high reaction activities of $\mathrm{OH}^{*}$ causing the rapid oxidation and cutting of $\mathrm{sp}^{2}$ carbon domains into smaller fragments without any destruction $[79,80]$. For example, in electro-oxidation process the free radicals $\left(\mathrm{OH}^{*}, \mathrm{O}^{*}\right)$ produced by the anodic oxidation of water cut the large $\mathrm{sp}^{2}$ carbon domains of graphene into GQDs without hampering the original $\mathrm{sp}^{2}$ structure [55]. GQDs have been synthesized by the electrochemical scissoring of different carbon materials such as wood charcoal [55], carbon nanotubes [89], reduced graphene oxide (RGO) films [90], graphite rods [91], and 3D graphene [83, 89-91]. The anodic oxidation of water results in the formation of hydroxyl and oxygen free-radicals $\left(\mathrm{OH}^{*}, \mathrm{O}^{*}\right)$ which work as electrochemical scissors to generate GQDs (Fig. 4d) [88]. This process starts at the edge sites and hastens at the defect sites. For accelerating this cleavage process, defects maybe introduced into the lattice by doping. Heteroatoms or functional groups can be introduced to GQDs depending on the electrolyte used [83, 92, 93]. This electrochemical approach is quite simple and generally of high yield.[93] Recently, Nirala et al. reported on the one step electrochemical route for the synthesis of GQDs from wood charcoal, a kind of biomass [55]. Electrochemical oxidation of charcoal was performed by using it as a working electrode in ammonium persulfate electrolyte at $5 \mathrm{~V}$ potential. Anodic oxidation of water generated ${ }^{*} \mathrm{O}_{2}$ and $* \mathrm{OH}$ free radicals. These free radicals act as "scissors" to cut the graphene sheets of charcoal into very small particles, called E-GQDs [55]. This study brought one step closer toward the facile and green synthesis of GQDs from biomass precursor. Table 1 lists the various biomass resources for GQDs synthesis via different techniques.

\subsection{Bottom-up methods}

The bottom-up processes consist of synthesizing GQDs through chemical assembling of the small organic building blocks. The main reaction mechanism involved in these methods is the intermolecular coupling or carbonation process. 


\subsubsection{Intermolecular coupling}

These methods are beneficial for the synthesis of GQDs with controlled size and shape. GQDs have been synthesized with high precision through step-by-step organic synthesis, although low-output and strong pi-pi interaction causing aggregation was difficult to prevent $[89,94]$. GQDs can be prepared through hydrothermal carbonization reaction of the small organic frameworks [95]. Heating the small organic molecules above their melting point leads to condensation, nucleation, and subsequently the formation of larger C-Dots or GQDs. Numerous precursors have been utilised in this technique, such as organic salts [96,97], coffee grounds [75, 98], citric acid [99, 100], ascorbic acid [101], glycerol [102], etc.

The bottom-up approach is highly valuable for preparing GQDs with tuneable size through biomass precursors. Kalita et al. reported on the controlled growth of GQDs from rice grains [103]. Rice grains were heated in cooking pan for different time spans to synthesise GQDs with size of $2 \mathrm{~nm}$ to $6.5 \mathrm{~nm}$. When rice powder is heated, the thermal degradation of starch leads to the formation of glucose oligomers. These oligomers start to nucleate at high temperature $\left(200^{\circ} \mathrm{C}\right)$, which subsequently grow by pyrolization to form a GQD (Fig. 5a). The growth is controlled by the heat treatment time, leading to the tunable size distribution of GQDs. Similarly, honey is used as a carbohydrates precursor to synthesize GQDs with tuneable size via emulsion-templated method (Fig. 5b) [104]. Aqueous solution of honey was emulsified in 1-butanol and heated at $80{ }^{\circ} \mathrm{C}$ under vigorous stirring for $1 \mathrm{~h}$. As a result, the GQDs with a size of $2.4 \mathrm{~nm}$ were produced and found promising application in stable security ink and white light emission applications [104]. 

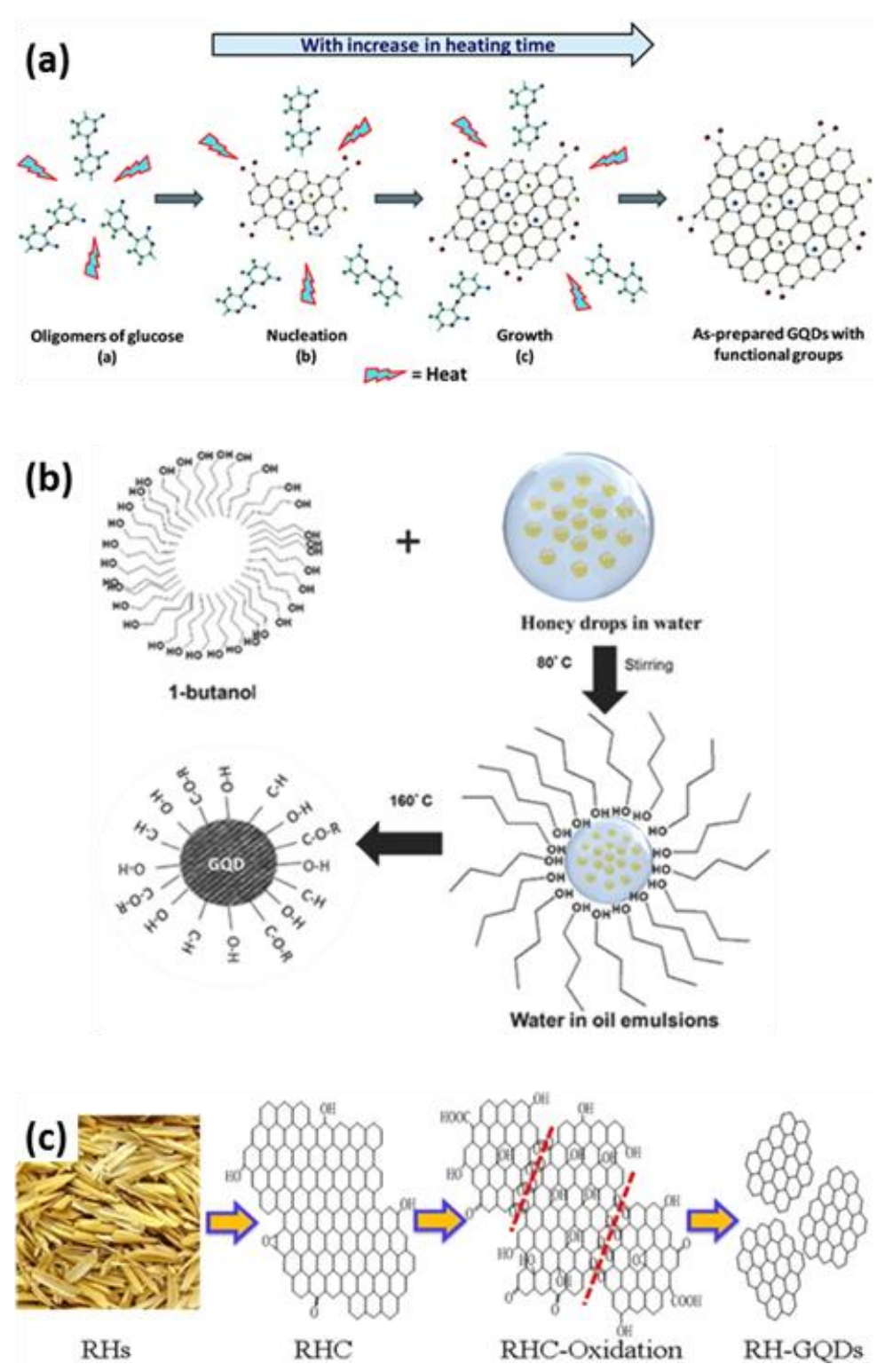

Fig. 5. (a) Bottom-up method for the synthesis of GQDs from rice grains. Reprinted with permission from ref. [103]. Copyright (2016) Royal Society of Chemistry. (b) Emulsion-templated carbonization of honey for the synthesis of GQDs. Reprinted with permission from Ref. [104]. Copyright (2015) Wiley Publishing Group. (c) Top-down joint approach for the synthesis of GQDs. Reprinted with permission from ref. [73]. Copyright (2016) American Chemical Society.

Interestingly, in these bottom-up processes, doping effects of heteroatoms can be conveniently achieved from precursor materials. Nitrogen doped GQDs, for example, have been produced by hydrothermal techniques using citric acid as a source of carbon and ethanol amine, diethylene amine, ethylene diamine or urea as a source of nitrogen [105]. The concentration of nitrogen doping and luminescence yield principally depends on nitrogen precursor selected [93, 105]. Similarly, Sulfur doped monodispersed GQDs have been synthesized through hydrothermal treatment of fructose using sulfuric acid as sulphur source [106]. 
Table 1. A brief overview of the GQDs synthesis from various types of biomass via a number of approaches.

\begin{tabular}{|c|c|c|c|c|c|c|}
\hline Precursor & Preparation approach & Product & $\begin{array}{l}\text { Yield } \\
(\text { wt. \%) }\end{array}$ & $\begin{array}{l}\text { Size } \\
(\mathrm{nm})\end{array}$ & $\begin{array}{c}\text { Height } \\
(\mathrm{nm})\end{array}$ & Ref. \\
\hline Neem leaves & $\begin{array}{l}\text { Pyrolysis and hydrothermal } \\
\text { treatments }\end{array}$ & $\begin{array}{c}\text { GQDs, } \\
\text { Am-GQDs }\end{array}$ & - & $5-6$ & $0.4-1.7$ & [74] \\
\hline Rice Husks & $\begin{array}{l}\text { Pyrolysis, hydrothermal } \\
\text { treatment }\end{array}$ & GQDs & 15 & $3-6$ & $0.8-1.6$ & [73] \\
\hline Wood charcoal & Electrochemical oxidation & GQDs & - & $3-6$ & $\sim 6$ & [55] \\
\hline Coffee grounds & Hydrothermal treatment & $\begin{array}{c}\text { GQDs, } \\
\text { PEI-GQDs }\end{array}$ & 33 & $\begin{array}{c}1.88 \text { (GQDs) } \\
2.67 \text { (PEI- } \\
\text { GQDs) }\end{array}$ & $\begin{array}{c}2.23 \text { (GQDs) } \\
3.18 \text { (PEI- } \\
\text { GQDs) }\end{array}$ & [75] \\
\hline Neem leaf extract & $\begin{array}{l}\text { Pyrolysis, hydrothermal } \\
\text { treatment }\end{array}$ & GQDs & 25.2 & $2-8$ & - & [72] \\
\hline $\begin{array}{c}\text { Fenugreek leaf } \\
\text { extract }\end{array}$ & $\begin{array}{l}\text { Pyrolysis, hydrothermal } \\
\text { treatment }\end{array}$ & GQDs & - & $3-10$ & - & [72] \\
\hline Honey & $\begin{array}{c}\text { Emulsion templated } \\
\text { carbonization }\end{array}$ & GQDs & - & $1.8-2.8$ & - & [104] \\
\hline Rice grains & Pyrolysis & GQDs & 56 & $2-6.5$ & $1-2$ & [103] \\
\hline
\end{tabular}

\subsubsection{Reaction mechanism}

As discussed in previous section, most of the reports on biomass derived GQDs focused on controlling the properties via different techniques. However, the detailed reaction mechanism is not well understood. In order to develop a strong structure-property-application relationship, in depth understanding of the reaction mechanism is mandatory. It was reported initially that heating the small organic molecules above their melting point leads to condensation, nucleation, and subsequently the formation of larger C-Dots or GQDs. Subsequently, many researchers suggested that the bottom-up approach involve two major reactions, dehydrogenation and carbonization. The dehydrogenation and carbonization of small molecules under hydrothermal or solvothermal conditions produce GQDs. However, there are still some challenges associated with this reaction mechanism. The complex dehydrogenation and carbonization process results in the introduction of heteroatoms on the surface or edges rather than lattice doping.

Recently, Dr Yang's group reported on the detailed mechanism for the synthesis of sulfur (S) doped GQDs from biomass (durian) [107]. They elaborated the source of C and S, its doping in the lattice structure and controlling the doping concentrations in a systematic way. Low molecular weight saccharides and mercaptans constituents of durian are suggested to be the main source of $\mathrm{sp}^{2}$ carbon network and $\mathrm{S}$ doping, respectively, in the preparation of S-GQDs. 
Elsewhere [108], they demonstrated that general mechanism proceeds by the abstraction of $\mathrm{H}$ from $\mathrm{C}-\mathrm{H}, \mathrm{N}-\mathrm{H}, \mathrm{S}-\mathrm{H}$, etc. bonds, resulting in generation of respective $\mathrm{H}, \mathrm{C}, \mathrm{N}$, and $\mathrm{S}$ atoms with dangling bonds. Subsequently, the formation of C-C, C-N/C-S bonds take place between the growing monomers, followed by release of hydrogen. These monomers then combine to form $\mathrm{sp}^{2}$ network of carbon with $\mathrm{N}$ or $\mathrm{S}$ doping in the lattice structure [108]. The high resolution XPS analysis of S 2p spectrum showed two peaks $(\sim 163.9 \mathrm{eV}, \sim 165.1 \mathrm{eV})$ corresponding to thiophene structure (Fig. 6a), suggesting the $S$ doping to be mainly in the form of thiophene inside the lattice. The mechanism of $\mathrm{S}$ doping was proposed to be substitutional as shown schematically in Fig. 6b. The doping concentration was controlled systematically with heating time and temperature. The doping concentration decreases linearly with increasing reaction time or temperature due to the removal effect of heteroatom in the $\mathrm{sp}^{2}$ carbon structure under high temperature or long reaction times [107]. Further demonstrations indicated that PL behaviour and quantum yield changes significantly with doping concentrations. PL emission of S-GQDs was suggested to continuously shift from blue to red with increasing the doping concentration. PL shift is attributed to the change in total amount of oxygen containing functional groups due to lattice replacement of $\mathrm{S}$ atoms in $\mathrm{sp}^{2} \mathrm{C}$ network [108]. Variation in quantum yield is induced by $n-\pi^{*}$ transition which is the key factor for high quantum yield [93].
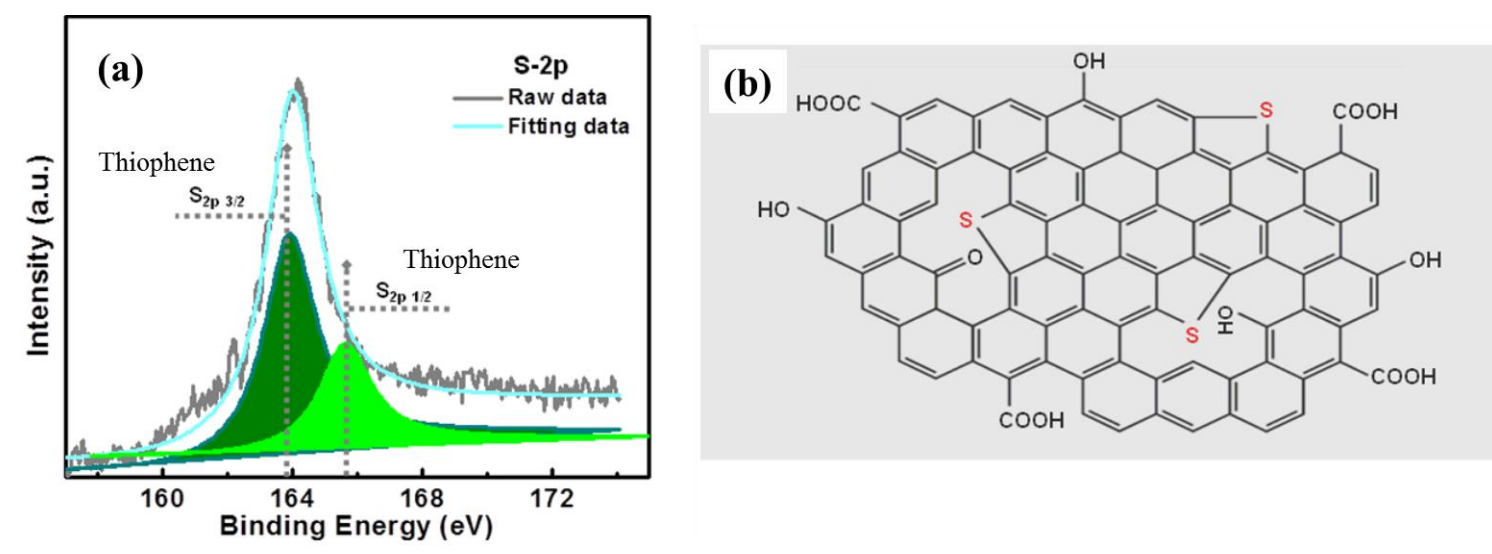

Fig. 6. (a) High-resolution XPS S $2 p$ spectrum showing the thiophene presence in the skeleton of S-GQDs. and (b) schematic diagram representing the $S$ doping in lattice substitutional manner in the structure of S-GQDs. Reprinted with permission from ref. [107]. Copyright (2018) American Chemical Society.

\subsection{Up-Down joint approach}

Recently a new approach was developed by combining the both top-down and bottom-up techniques, making the large scale synthesis of GQDs possible from various precursors 
including biomass waste [73]. This approach first converts the biomass waste into large area $\mathrm{sp}^{2}$ carbon flakes through a "bottom-up" method and then hydrothermally cut carbon flakes into small pieces of $\mathrm{sp}^{2}$ carbon domains by a "top-down" method (Fig. 5c) [73]. The whole process is simple, easy and scalable for mass production, leading to a high yield of GQDs [73]. Interestingly, GQDs with varying properties for intriguing potential applications can be obtained using this approach. For example, when the rice husk derived GQDs (RH-GQDs) dispersion is irradiated with $365 \mathrm{~nm}$ ultraviolet lamp, an intense blue light is emitted, indicating its possible application in bio-imaging and photonics [73].

\section{Modification approaches}

Numerous methodologies have been investigated for acquiring the defined and desired properties of GQDs, including synthetic and post-synthetic approaches. These strategies can be broadly divided into three major categories: (1) size and shape control, (2) surface modification, and (3) heteroatom doping.

\subsection{Size and shape control}

It is well understood $[109,110]$ that photoluminescence (PL) of GQDs is mainly dependent on its size due to quantum confinement and somehow on its shape due to edge effects. A good control over the shape and size of GQDs might be achieved through step-wise organic synthesis [111]. For example, well defined GQDs have been synthesized by ruthenium-catalysed cageopening of $\mathrm{C}_{60}$ molecules [112]. Moreover, Kalita et al. systematically synthesised a range of GQDs from biomass (rice grains) with a precise control over the size. The controlled growth of GQDs with size of 2 to $6.5 \mathrm{~nm}$ was achieved by tuning the heating time from 3 to $10 \mathrm{~min}$. The thermal degradation of starch present in rice grains generate glucose oligomers which polymerize to form GQDs. Increase in the polymerization times leads to the increase in the size of GQDs. The quantum yield of GQDs increase from 16 to $24 \%$ with decrease in size from 6.5 to $2 \mathrm{~nm}$.

The morphology GQDs can be varied from hexagonal, parallelogram, triangular, and trapezoid to mushroom shaped by alteration in the annealing temperature and carbon clusters' density [53]. SK et al. reported on the variation in PL emission with change in the size of pristine zig-zag edged GQDs (Fig. 7a) [109]. The fluorescence of as prepared GQDs changes from UV (bandgap $6.81 \mathrm{eV}$ ) to infrared (bandgap $1.64 \mathrm{eV}$ ) by tuning the size from 0.46 to 2.31 $\mathrm{nm}$ due to bandgap shrinkage induced by $\pi$-electron delocalization. PL emission is dictated by the isolated small $\mathrm{sp}^{2}$ domains of heterogeneously hybridised and large sized GQDs [53, 109]. 


\subsection{Surface modification}

Besides the prominent shape- and size-dependence, PL properties of GQDs can also be modified by surface engineering, including surface oxidation [113], polymer passivation, and chemical moieties attachment [114]. Introduction of the oxygenated functional groups on GQDs make them hydrophilic leading to the ease of further chemical functionalization. On the other hand, PL efficiency is affected due to the surface emissive traps induced by these groups. Therefore, a precise control over the degree of oxidation is necessary for the defined and desired properties. It is reported that quantum yield can be enhanced by the reduction of oxygenated GQDs, whereas the emission is red shifted by oxidation of GQDs (Fig. 7b) [109, 115-117]. For example, reduction of GQDs with $\mathrm{NaBH}_{4}$ blue-shifted the PL emission and increased the quantum yield by two times [118]. An attractive strategy to enhance the quantum yield of GQDs is the polymer passivation of surface emissive traps. Various polymers have been reported for surface passivation, most common of which is polyethylene glycol (PEG) [119-121]. With a thin layer of PEG, quantum yield of GQDs was doubled [120]. However, surface passivation imposes limitations on the applications due to the complicated process and increased particle size of passivated GQDs. Furthermore, a number of chemical groups, such as thiol [31], diamine[93], alkylamine [116], hydrazide [122], etc., have been attached onto the GQDs. These electron donating groups prevent the non-radiative recombination and usually cause wavelength shift thereby enhancing the quantum yield [116]. For example, green oxygenated GQDs turned blue when carboxyl group was replaced with alkylamine [116]. Tetsuka et al. demonstrated that precise control over the degree of amine functionalization could widely tune the emission wavelength of GQDs (blue to yellow) [123].

Similarly, the properties of biomass-waste derived GQDs have also been modified by surface engineering, especially by addition of various functional groups and passivating agents. Similar to Zhu et al. modification approach, Suryawanshi et al. modified the Neem leaves derived GQDs by amine (- $\mathrm{NH}_{2}$ ) functionalization to enhance the PL properties [74]. The green luminescence of unmodified GQDs changed to blue after amine functionalization. This PL shift is attributed to the decrease in agglomeration and changes in the oxygenated functional groups into $-\mathrm{CONH}_{2}$ and $-\mathrm{C}-\mathrm{NH}_{2}$ surface groups, which suppress the non-radiative recombination path, resulting in the improvement of PL intensity and quantum yield by a factor of two. Kalita et al. modified the GQDs with amine functionalization in a similar manner to enhance the quantum yield of rice grains derived GQDs [103]. The quantum yield was improved $125 \%$ after amine functionalization due to superior electron donating ability of amine groups. 
Wang et al. functionalized the coffee ground derived GQDs with poly(ethylene imine) (PEI) to obtain the excitation independent emission [75]. The blue fluorescence of as prepared GQDs changed to strong cyan fluorescence and quantum yield enhanced three folds after PEI functionalization. The excitation independent emission behaviour of PEI functionalized GQDs implies that size and surface states of $\mathrm{sp}^{2}$ clusters contained in the GQDs should be more confined.

\subsection{Heteroatom doping}

Recently, heteroatom doping (most often nitrogen doping) has emerged as a promising technique to fine tune the physicochemical properties (PL, quantum yield, etc.) of GQDs [124]. Heteroatom can be added through the precursor materials during synthesis or via post synthesis techniques. Heteroatom doping via precursor material has become a popular technique in the synthesis of biomass derived GQDs [107, 124]. Sulfur doping red-shifts the PL emission and enhances the quantum yield. Very recently, Wang et al. prepared a series of GQDs with controllable sulfur (S) doping using durian (a biomass) as a precursor material, as well as the source of sulfur [107]. The doping concentration was controlled via reaction time. With increase in the reaction time, doping decreases linearly due to the removal effect of heteroatom in $\mathrm{sp}^{2}$ carbon structure under long reaction times. The doping concentration of heteroatom significantly determines the PL behaviour of GQDs. The PL spectra of sulfur doped GQDs substantially shifts with change in the doping concentration and demonstrate a red shift behaviour with increase in the doping concentration. A wide broadband of PL emission (420$620 \mathrm{~nm}$ ) from S doped GQDs can be acquired by variation in the doping concentration [107]. It has been repeatedly reported that nitrogen-doping improves the quantum yield and blue shifts the PL emission (higher the N-doping, shorter the emission wavelength) of GQDs due to the high electronegativity and electron withdrawing properties of nitrogen atoms $[92,109,125$, 126]. Some researchers proposed that $\mathrm{N}$-doping can also offer up-conversion PL properties to GQD [119]. The catalytic properties and PL characteristics of GQDs have also been configured by doping with various other elements such as S [106], P [127], Si [128], and B [129]. For example, quantum yield of GQDs as high as $71 \%$ have been acquired by $\mathrm{S}$ and $\mathrm{N}$ co-doping [130]. 

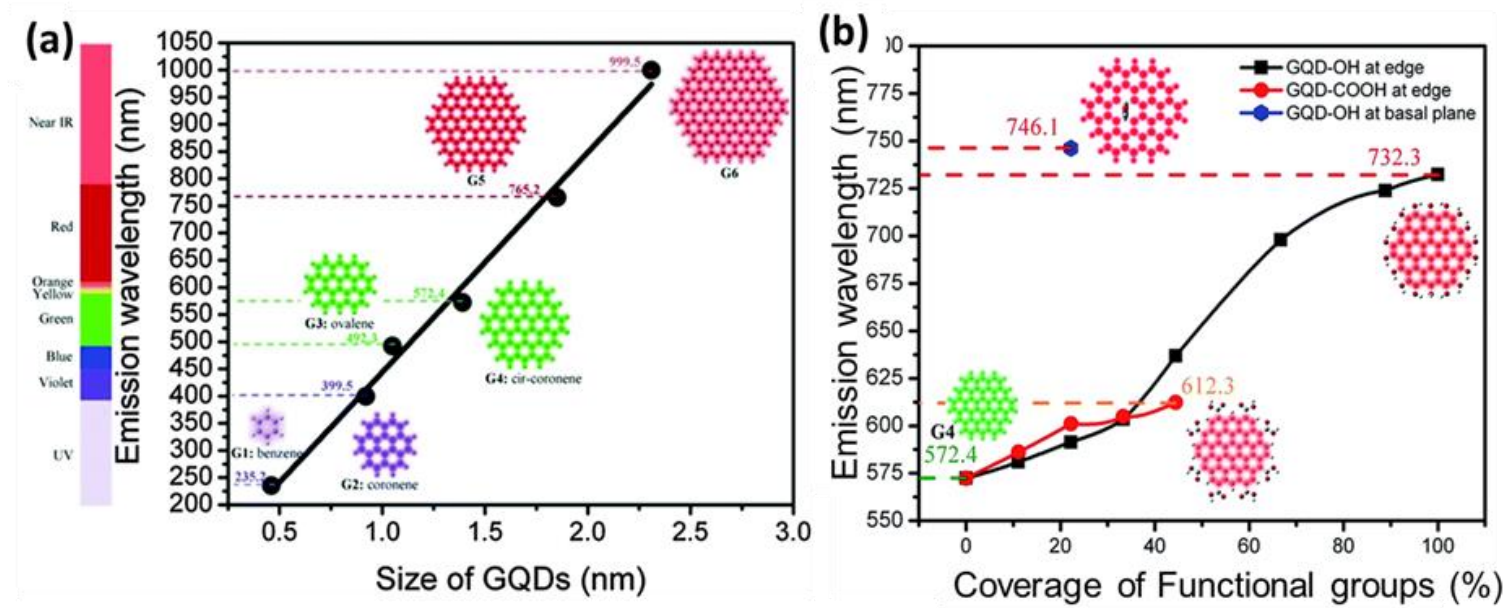

Fig. 7. (a) Calculated emission wavelength of zig-zag edged GQDs as a function of size. (b) Emission wavelength of oxidized GQDs as function of coverage of $-\mathrm{OH}$ and-COOH groups. Adopted and modified with permission from ref. [109]. Copyright (2014) Royal Society of Chemistry.

The introduction of surface functional groups and defects cause a red shift in the PL emission of GQDs while pyrrolic N-doping and armchair edges cause the blue-shift $[62,92$, 109]. PL properties of GQDs are governed by a combination of defect and intrinsic state emission. The former is a result of energy trap states owning to the dopants, chemical groups, or vacancy defects while quantum confinement, edge effects and the radiative recombination of electron-hole pairs are the major driving factors for the later. Synthesizing GQDs with homogeneous properties is challenging because of their high tenability [62]. On the positive side, it bestows GQDs a broad range of fascinating properties. Heteroatom doping, for example, enhances the fluorescence quantum yield [93, 105] and imparts GQDs an interesting upconversion property which can be attributed to a multiphoton active process or an anti-Stokes transition [71, 119].

\section{Applications of biomass derived GQDs}

Graphene as a noble material, has triggered a gold rush to exploit its potential for energy storage/conversion applications [14, 131-134]. The main factor behind the attraction and significance of graphene in energy devices is its large specific surface area and high electrical conductivity [135]. Nevertheless, graphene as an electrode material faces a considerably reduced surface area owing to the irreversible agglomeration or restacking of graphene sheets by the strong $\pi-\pi$ bonding and van der Waals interactions between them, consequently limiting its practical applications $[135,136]$. In addition to graphene, RGO has also been utilized in energy devices but its reduced electrical conductivity due to its defective nature limits its 
commercial applications $[132,137]$. To this end, GQDs stand out as a new material combining the exceptional properties of both graphene and quantum dots [68]. As a result of the intriguing properties, such as good electrical conductivity, enlarged surface area, high solubility in many solvents, strong luminescence, high mobility, decreased chemical impedance, and tunable bandgap [56, 68, 90, 95, 130], GQDs exhibit an edge over other graphene based materials and have indicated a bright promise in fluorescence sensors [74, 138-140], photovoltaic devices [90, 141], light-emitting diodes [142, 143], solar cells [144, 145], fuel cells [92, 146], batteries [147, 148], and supercapacitors.[149, 150]. Herein, the numerous applications of biomass derived GQDs are presented.

\subsection{PL sensors}

In the context of strong luminescence properties, GQDs have been used to detect different analytes [74, 139, 140]. Wang et al. [138] reported on the GQD based PL sensor for the first time and demonstrated that the luminescence of GQDs can be quenched selectively by $\mathrm{Fe}^{3+}$ ion through charge transfer mechanism. Chi et al. developed a selective, sensitive and relatively green PL sensor for detection of chlorine in water [139]. This advancement indicates that not only the cations but anions can also be detected selectively by GQDs based sensors. Inspired by these studies, biomass derived GQDs have also been investigated for detection of heavy metal ions in water based on their strong fluorescence properties $[74,75]$.
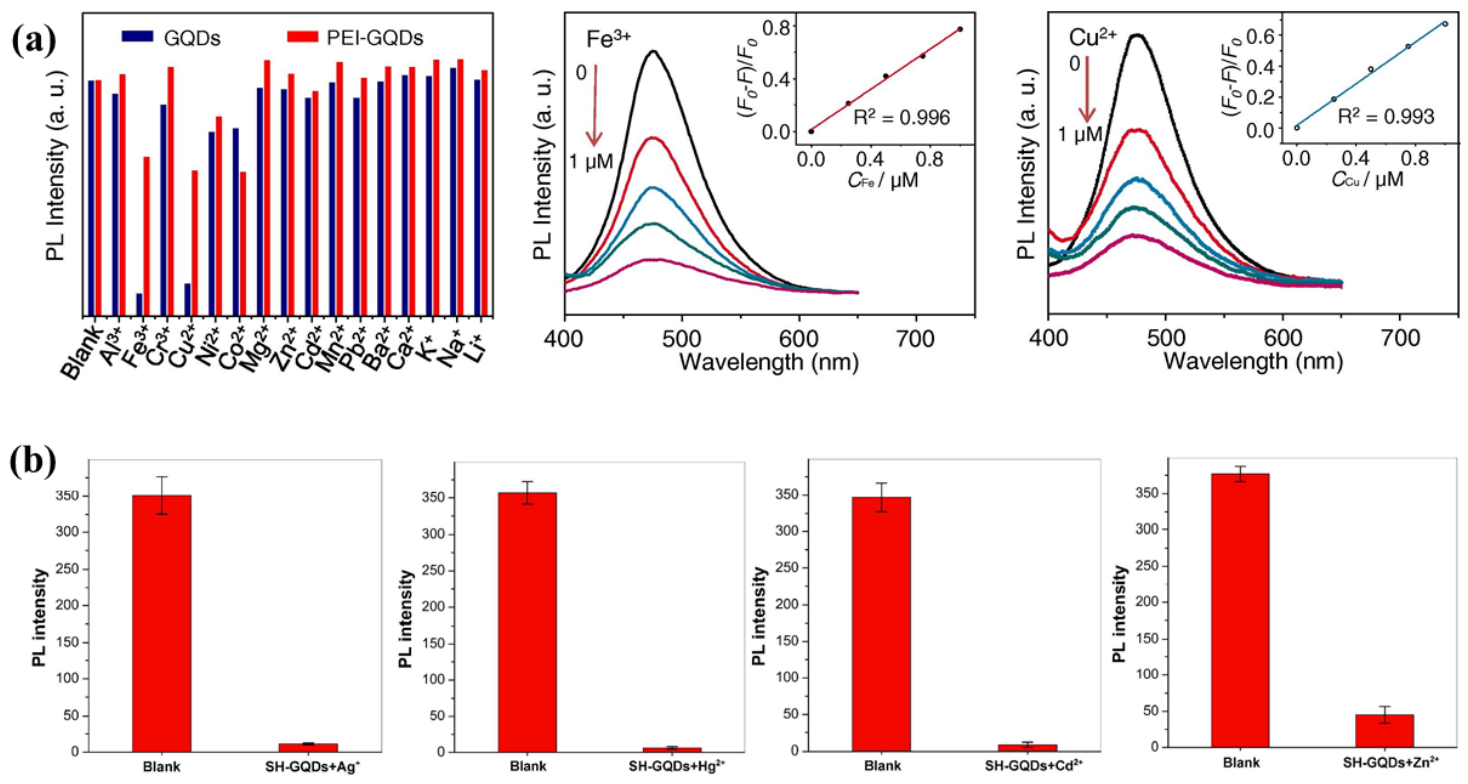

Fig. 8. (a) Difference among the PL intensity of PEI functionalized GQDs without (blank) and with the addition of different metal ions, and variation in the PL intensity with change in the concentration of $\mathrm{Fe} 3+$ and $\mathrm{Cu} 2+$ ions. Reprinted with permission from ref. [75]. Copyright 2016 Elsevier. (b) Difference in the PL intensity of GQDs between blank and heavy metal ions $\left(\mathrm{Ag}^{+}, \mathrm{Hg}^{2+}, \mathrm{Cd}^{2+}, \mathrm{Zn}^{2+}\right)$ added solution. Reprinted with permission from ref. [107]. Copyright (2018) American Chemical Society. 
$\mathrm{Wu}$ et al. reported on the coffee grounds derived PEI functionalized GQDs as a PL sensor for the detection of $\mathrm{Fe}^{3+}$ and $\mathrm{Cu}^{2+}$ ions for environment analysis (Fig. 8a) [75]. The PL quenching mechanism was attributed to the strong binding affinity and chelating effect of $\mathrm{Fe}^{3+}$ and $\mathrm{Cu}^{2+}$ ions with $\mathrm{N}$ functional groups of PEI functionalized GQDs. Recently, Ding et al. reported on the preparation of GQDs from Durian and modified by sulfhydryl to prepare a PL sensor for the detection of a range of metal ions $\left(\mathrm{Ag}^{+}, \mathrm{Hg}^{+}, \mathrm{Cd}^{+}\right.$, and $\left.\mathrm{Zn}^{+}\right)$(Fig. 8b) [107].

Apart from switch-OFF PL sensors, switch ON-OFF-ON sensors have been developed from biomass derived GQDs [74, 75]. Suryawanshi et al. reported on the synthesis of amineterminated GQDs from biomass as an efficient and selective ON-OFF-ON sensor for detection of $\mathrm{Ag}^{+}$ion in water owning to their strong luminescence and specific functionalization [74]. Fluorescence intensity of am-GQDs was quenched by the addition of different metal ions such as $\mathrm{Co}(\mathrm{II}), \mathrm{Cu}(\mathrm{II}), \mathrm{Ni}(\mathrm{II}), \mathrm{Fe}(\mathrm{II}), \mathrm{Fe}(\mathrm{III}), \mathrm{Hg}(\mathrm{II})$ and $\mathrm{Pb}(\mathrm{II})$.

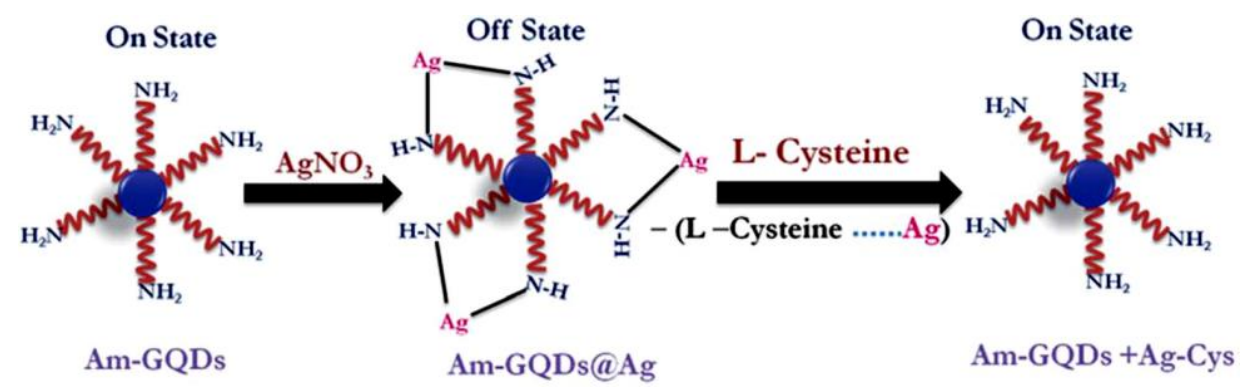

Fig. 9. Schematic of the suggested mechanism for detection of Ag+ ions by Am-GQDs' $P L O N-O F F-O N$ states induced through the addition of $\mathrm{AgNO}_{3}$ and L-cysteine. Reprinted with permission from ref. [74]. Copyright (2014) Royal Society of Chemistry.

Although the fluorescence of Am-GQDs was quenched by the different metal ions but this system was modified for the selective detection of Ag+ ions. This was accomplished by the use of an amino acid "L-cysteine" which has strong affinity towards Ag+ ions. By the addition of L-cysteine into the Am-GQDs- $\mathrm{Ag}^{+}$system, the quenched fluorescence was regenerated due to removal of $\mathrm{Ag}^{+}$ion from Am-GQDs and attachment with -SH group of L-cysteine (Fig. 9). Mechanism for such a selective detection was illustrated by the Pearson's hard-soft acid base (HSAB) theory.

\subsection{Light-emitting diodes}

In contrast to the significant studies on GQDs based LEDs [63, 151], there has been a few reports demonstrating the biomass derived GQDs usage in LEDs. It was first reported that LEDs employing GQDs as dopant exhibit white electroluminescence having an external quantum efficiency of $0.1 \%$ [152]. Later on, Roy et al. reported on the development of white light emitting diode based on the Neem leaves derived GQDs [72]. As prepared GQDs emit 
green luminescence with high quantum yield of $41.2 \%$. The white light emitting material was developed by mixing the green light emitting GQDs with blue light emitting quinine sulphate and red light emitting chlorophyll solutions in PMMA at an optimized ratio. The resultant mixed solution was coated onto a laboratory-made PET cap which was fitted onto a near UV LED and excited to emit white light (Fig. 10a, b).
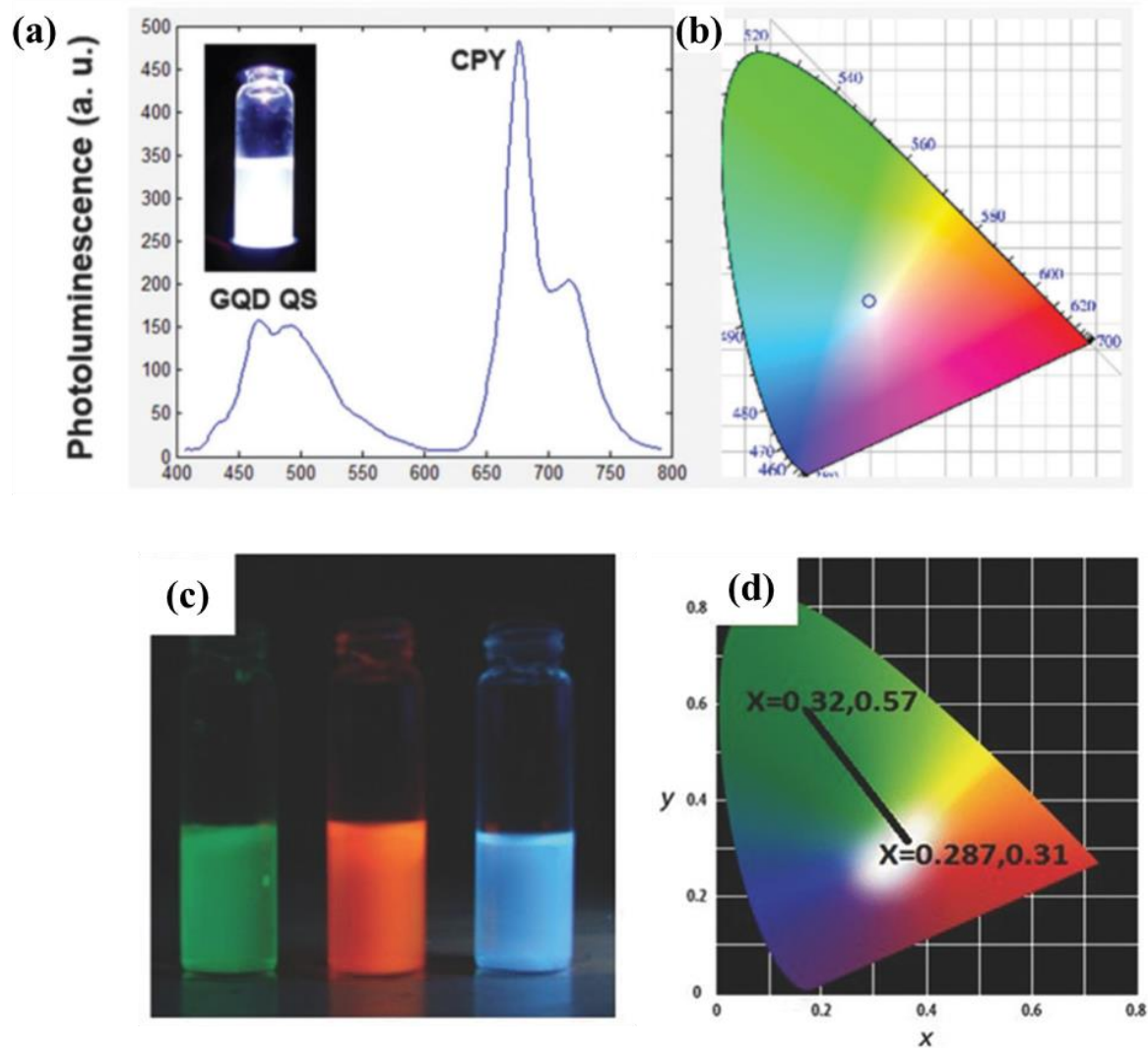

Fig. 10. PL spectra of GQDs, QS and CPY solution coated on PET cap (inset is the photograph of the solution illuminated by near UV LED, showing white light emission), (b) corresponding color coordinate, CIE spectrum after excitation with nearUV LED light. Reprinted with permission from ref. [72]. Copyright (2014) Centre National de la Recherche Scientifique and Royal Society of Chemistry. (c) GQDs, RhB, and the mixture showing white light emission, (d) color coordinate for the mixture of GQDs-RhB solution showing white light emission. Reprinted with permission from ref. [104]. Copyright (2016) Wiley Publishing Group.

Similarly, Mahesh et al. prepared a GQDs from Honey for white light emission [104]. When these purely green light emitting GQDs were mixed with Rhodamine B having an orange red fluorescence, the resulting solution showed white light emission upon excitation at $340 \mathrm{~nm}$ (Fig. 10c,). The CIE 1931 chromaticity coordinates for GQDs after mixing suggested the emission of highly pure white light (Fig. 10d). Thus, these GQDs can be used for producing white light emitting diodes and other devices. 


\subsection{Biomedical applications}

Biomass derived GQDs have been widely investigated for biomedical applications, especially bioimaging. Among a number of different types, the GQDs derived from natural food precursor such as rice grains [103], rice husks [73], coffee beans [75] and so on, are suggested to be the promising candidate for biomedical applications. Wang et al. reported on the biomedical applications of GQDs derived from rice husk biomass [73]. Rice husks (RH) were reported to be an abundant source for the controllable preparation of high quality $\mathrm{RH}-$ GQDs suitable for bioimaging of Hela cells. The biocompatibility of the RH-GQDs was investigated by analysing the toxicity and cell viability of Hela cells after treatment with various concentrations of RH-RH-GQDs. At low concentrations of RH-GQDs $(20-50 \mu \mathrm{g} / \mathrm{ml})$ almost no toxicity even after $48 \mathrm{~h}$ and over $90 \%$ cell viability was observed up to $100 \mu \mathrm{g} / \mathrm{ml}$ concentration (Fig. 11a). No obvious damage to the cell morphology was observed which indicate the high biocompatibility of RH-GQDs for bioimaging applications. Furthermore, in vitro bioimaging of Hela cells with RH-GQDs $(50 \mu \mathrm{g} / \mathrm{ml})$ was investigated and the cells combined with the RH-GQDs showed blue fluorescence with cell morphology and cytoplasm clearly presented (Fig. 11b). The luminescence of Hela cells in the presence of RH-GQDs is quite stable showing the feasibility of this biomedical system.
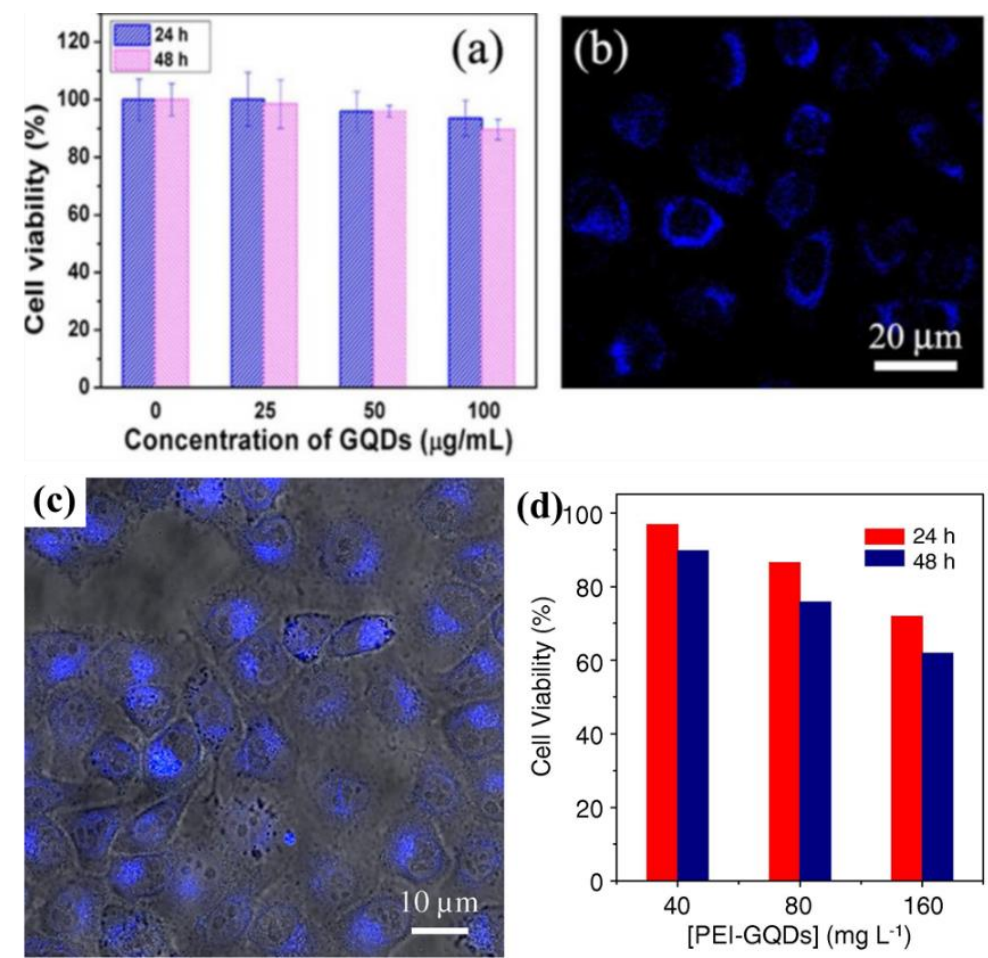

Fig. 11. (a)Viability of Hela cells incubated with different concentrations of RH-GQDs after a period of 24 and $48 \mathrm{~h}$, (b) imaging of the Hela cells combined with $50 \mu \mathrm{g} / \mathrm{mL}$ of $R H-G Q D s$ at $335 \mathrm{~nm}$ with a confocal microscope. Reprinted with permission from ref. [73]. Copyright (2016) American Chemical Society. (c) Confocal microscope image at $405 \mathrm{~nm}$ excitation 
of Hela cells using PEI-GQDs, (d) cytotoxicity assessment of PEI-GQDs at different doses for incubation period of 24 and 48 $h$ using Hela cells. Reprinted with permission from ref. [75]. Copyright 2016 Elsevier.

Wu et al. developed a fluorescent probe for bioimaging of the Hela cells based on the GQDs derived from coffee grounds [75]. Hela cells were cultured in $40 \mathrm{mg} / \mathrm{L}$ dose of GQDs and images were taken at $405 \mathrm{~nm}$ using a confocal microscope (Fig. 11c). Enhanced fluorescence of cytoplasm around their nucleus indicate the penetration of GQDs into the cells and their emissive stability. The PEI functionalized GQDs show brighter imaging owning to their high quantum yield. The cytotoxicity and cell viability results indicate the high biocompatibility of these GQDs even after $24 \mathrm{~h}$ of incubation period at low dosage of $40 \mathrm{mg} / \mathrm{L}$ (Fig. 11d).

Similarly, Kalita et al. prepared GQDs from rice grains and evaluated their bioimaging compatibility and biocompatibility with Hela cells [103]. GQDs treated Hela cells were imaged using 375, 488 and $561 \mathrm{~nm}$ laser and strong green and blue fluorescence was observed. Strong green and blue fluorescence indicate that GQDs are present as agglomerates in the nucleus and cytoplasm sites of the cells. After treatment cells do not show any obvious morphological damage, indicating the good biocompatibility of GQDs for bioimaging applications. A cell viability of over $90 \%$ was observed after $24 \mathrm{~h}$ incubation period at different concentrations of GQDs up to $1 \mathrm{mg} / \mathrm{ml}$. Very low cytotoxicity and high cell viability confirmed the biocompatibility of these GQDs for biomedical applications.
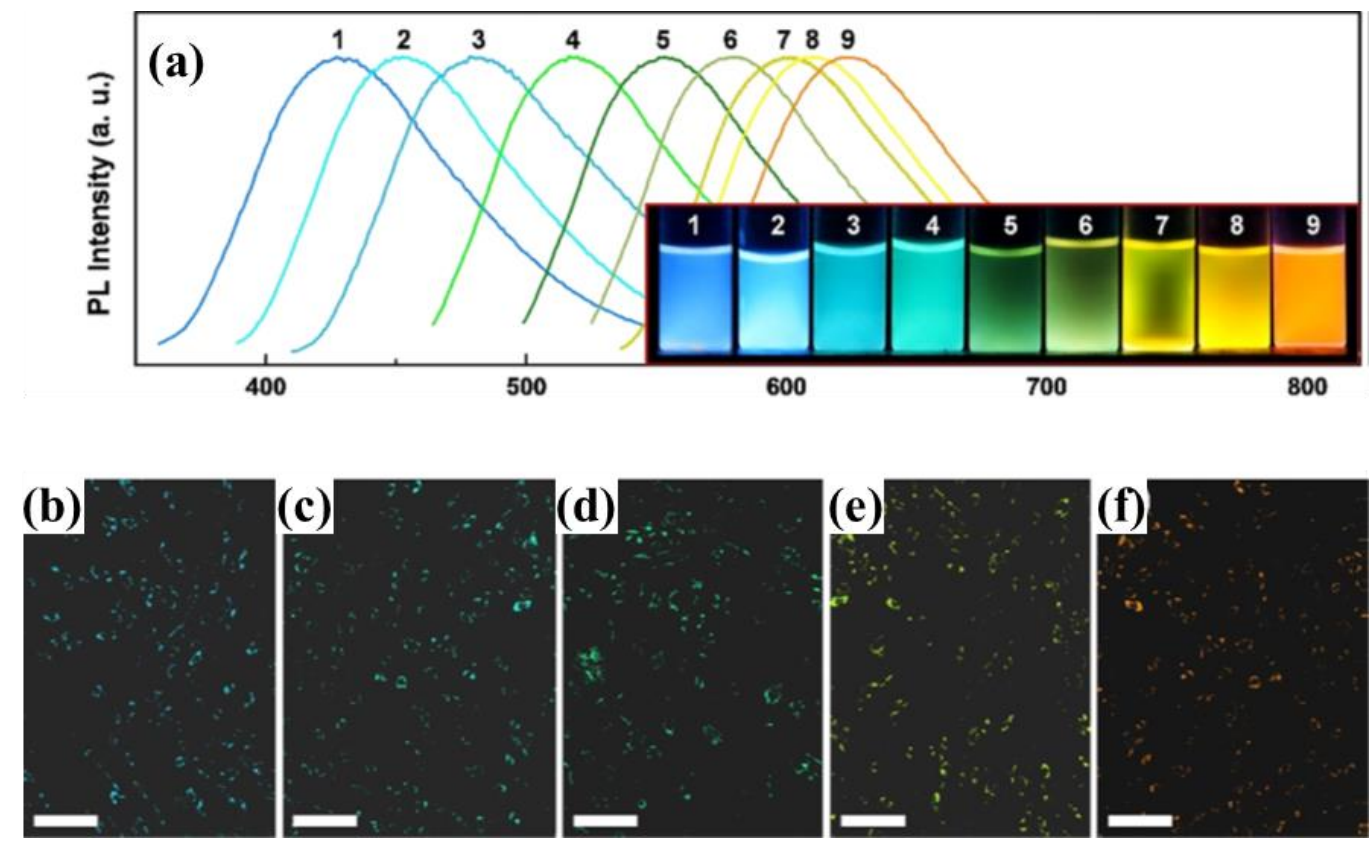

Fig. 12. (a) PL spectra of $S$-GQDs with varying concentration of heteroatom doping, and (b) respective imaging of fibroblast cells incubated with $S$-GQD series 1, 3, 5, 7, and 9 (scale bar: $20 \mu \mathrm{m}$ ). Reprinted with permission from ref. [107]. Copyright (2018) American Chemical Society. 
Very recently, Ding et al. reported on the bioimaging of fibroblast cells with sulfur doped GQDs synthesised by the hydrothermal treatment of durian [107]. Different GQDs with varying amount of $\mathrm{S}$ doping indicate different color in bioimaging of the fibroblast cells, showing their high bioimaging capability (Fig. 12).

\section{Energy applications of GQDs in general}

In addition to biomass, numerous different types of precursors (such as graphene, carbon fibre, CNTs, etc.) have been used to prepare GQDs aiming at different applications. GQDs derived from biomass have the properties similar to the ones derived from graphene based precursors, as verified in the synthesis section. Thus, regardless of the precursor being used, GQDs with various tunable properties have been implemented in energy application. Owning to their extraordinary properties, such as large surface area, good electrical conductivity, tunable luminescence, decreased chemical impedance, and tunable bandgap [56, 68, 90, 95, 130], GQDs have shown great promise in energy applications, such as photovoltaic devices [90, 141], batteries [147, 148], and supercapacitors [149, 150], as discussed below.

\subsection{Supercapacitors}

A number of two dimensional (2D) materials, such as graphene, graphitic carbon nitride, phosphorene, hexagonal boron nitride (h-BN), and transition metal dichalcogenide, have been extensively utilized in supercapacitors [124, 153-158]. In many cases, the quantum dot derivatives of these $2 \mathrm{D}$ materials exhibit superior performance due to their large specific surface area, abundant electrochemically active sites, ability to be easily integrated with various nanomaterials and low toxicity [62].

Liu et al. [150] synthesized a GQD-based symmetric micro-supercapacitor by electrophoretic deposition of GQDs on the interdigital Au finger microelectrode and acquired fast power response, high rate performance, and long cycling life (97.8\% stability after 5000 cycles) (Fig. 13a). They obtained a high specific capacitance of $534.7 \mu \mathrm{F} \mathrm{cm}^{-2}$ at a current density of $15 \mu \mathrm{A} \mathrm{cm}^{-2}$ with a power density of $7.5 \mu \mathrm{W} \mathrm{cm}{ }^{-2}$ and an energy density of 0.074 $\mu \mathrm{W} \mathrm{h} \mathrm{cm}{ }^{-2}$. These outstanding properties of micro-supercapacitor are credited to the role of GQDs. Particularly, the exceptionally small corresponding relaxation time constant $\left(\tau_{0}=103.6\right.$ $\mu \mathrm{s})$ of the GQD//GQD symmetric micro-supercapacitor indicates its extraordinary power response. With changing the aqueous electrolyte $\left(\mathrm{Na}_{2} \mathrm{SO}_{4}\right)$ to an ionic liquid electrolyte $\left(\mathrm{EMIMBF}_{4} / \mathrm{AN}\right)$, the corresponding relaxation time constant was further declined to $\tau_{0}=53.8$ $\mu$ s and as a result a seven times higher power and energy density was obtained. The potential 
window was further increased two times by fabricating one electrode (negative) coated with GQDs and the other (positive) modified with highly pseudo-capacitive nanomaterials, such as $\mathrm{MnO}_{2}$ or polyaniline (PANI) [150].

(a)
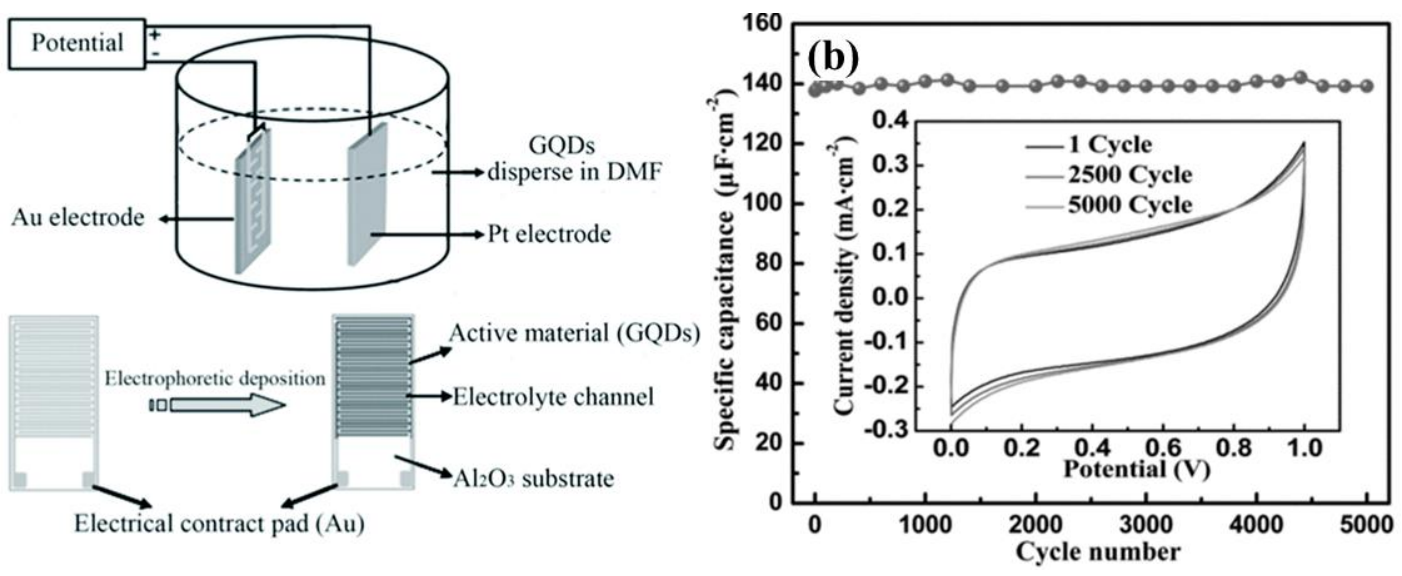

Fig. 13. (a) The preparation of a symmetric micro-supercapacitor by depositing GQDs on an interdigital Au finger microelectrode, (b) specific capacitance retention after 5000 cycles. Reprinted with permission from ref. [150]. Copyright (2013) Wiley Publishing Group.

The unique structure of these pseudo-capacitive materials helps accelerate the transport of electrolyte ions and provide abundant surface for the reactions involving charge transfer. The enhancement of specific capacitance and energy density in this asymmetric supercapacitor is based on the synergistic effects between negative and positive electrodes. $\mathrm{Hu}$ et al. [159] fabricated GQD/CNT hybrid film demonstrating a capacitance $\left(44 \mathrm{mF} \mathrm{cm}^{-2}\right)$ two times higher than the bare CNT film. 
Table 2. Comparison of the different parameters of the supercapacitors based on GQDs and other graphene derivatives.

\begin{tabular}{|c|c|c|c|c|}
\hline Materials & Preparation approaches & Performance & Characteristics & Ref. \\
\hline $\begin{array}{l}\text { GQDs-deposited on } \\
\text { interdigital Au finger }\end{array}$ & $\begin{array}{l}\text { Hydrothermal cutting } \\
\text { and electrophoretic } \\
\text { deposition }\end{array}$ & $\begin{array}{l}\text { Capacitance: } 534.7 \mu \mathrm{F} \mathrm{cm}^{-1} \text { at } 15 \\
\mu \mathrm{A} \mathrm{cm}^{-1} \text {, power density: } 0.074 \\
\mu \mathrm{W} \mathrm{cm}{ }^{-2} \\
\text { Rate performance: } 97.8 \% \text { after } \\
5000 \text { cycles }\end{array}$ & $\begin{array}{l}\text { Symmetric micro- } \\
\text { supercapacitor }\end{array}$ & [150] \\
\hline GQDs/ carbon fibre & In-situ direct grafting & $\begin{array}{l}\text { Rate performance: } 97 \% \text { after } \\
5000 \text { cycles at } 2 \mathrm{~A} \mathrm{~g}^{-1}\end{array}$ & Flexible, lightweight & [149] \\
\hline GQDs/PANI & Electrodeposition & $\begin{array}{l}667.5 \mu \mathrm{F} \mathrm{cm}^{-1} \text { at } 15 \mu \mathrm{A} \mathrm{cm}^{-1} \text {, } \\
\text { power density: } 7.5 \mu \mathrm{W} \mathrm{cm}^{-2}\end{array}$ & $\begin{array}{l}\text { Asymmetric micro- } \\
\text { supercapacitor }\end{array}$ & {$[160]$} \\
\hline GQDs/CNT & $\begin{array}{l}\text { Electrochemical, CVD, } \\
\text { electrodeposition }\end{array}$ & Capacitance: 44 mF cm ${ }^{-2}$, & $\begin{array}{c}\text { Symmetrical } \\
\text { supercapacitors }\end{array}$ & [159] \\
\hline GQDs/3D graphene & $\begin{array}{l}\text { Electrochemical } \\
\text { synthesis, } \\
\text { electrodeposition }\end{array}$ & Capacitance: $268 \mathrm{~F} \mathrm{~g}^{-1}$ & $\begin{array}{c}\text { Symmetrical } \\
\text { supercapacitors, Additive } \\
\text { free, monolithic }\end{array}$ & [161] \\
\hline GQDs/PANI nanotubes & Electrodeposition & $\begin{array}{l}\text { Capacitance: } 1044 \mathrm{~F} \mathrm{~g}^{-1} \text { at } 1 \mathrm{~A} \mathrm{~g}^{-1} \\
\text { Rate performance: } 80.1 \% \text { after } \\
3000 \text { cycles }\end{array}$ & $\begin{array}{l}\text { Asymmetric micro- } \\
\text { supercapacitor }\end{array}$ & [162] \\
\hline $\begin{array}{l}\text { Graphene/PANI } \\
\text { composite sheets }\end{array}$ & $\begin{array}{l}\text { Anodic electro- } \\
\text { polymerization }\end{array}$ & Capacitance: $233 \mathrm{~F} \mathrm{~g}^{-1}$ & Free standing, flexible & [163] \\
\hline $\mathrm{MnO}_{2} /$ graphene/GF & $\begin{array}{l}\text { Hydrothermal process, } \\
\text { electrodeposition }\end{array}$ & Capacitance: $9.6 \mathrm{mF} \mathrm{cm}^{-2}$ & $\begin{array}{l}\text { Wearable, flexible, all } \\
\text { solid state }\end{array}$ & [164] \\
\hline CNT/graphene hybrid & Hydrothermal, CVD & $\begin{array}{c}\text { Capacitance: } 0.74 \mathrm{mF} \mathrm{cm}^{-2} \text { at } 10 \\
\mathrm{~mA} \mathrm{~cm}{ }^{-2}\end{array}$ & Wearable, flexible & [165] \\
\hline $\begin{array}{c}\text { GF@3D G core-sheath } \\
\text { fibre }\end{array}$ & $\begin{array}{l}\text { Hydrothermal } \\
\text { treatment, } \\
\text { electrodeposition }\end{array}$ & Capacitance: $1.2-1.7 \mathrm{mF} \mathrm{cm}^{-2}$ & Wearable, flexible & [166] \\
\hline
\end{tabular}

Chen et al. [161] reported on additive free monolithic electrode based on 3D graphene/GQD composite. Astonishingly, the conductivity of 3D graphene structure was increased 10 times by the introduction of GQDs with a specific capacitance of $268 \mathrm{~F} \mathrm{~g}^{-1}$, demonstrating a progress of $490 \%$ over undecorated 3D graphene. Mondal et al. reported on the high performance supercapacitor based on GQD modified PANI nanofibers via chemically oxidizing aniline in the environment of GQDs [162]. Fig. 14a represents the preparation scheme of GQD/PANI composite. They achieved a large specific surface area, high aspect ratio, and a specific capacitance of $1044 \mathrm{~F} \mathrm{~g}^{-1}$ at a current density of $1 \mathrm{~A} \mathrm{~g}^{-1}$ (Fig. 14b). They observed a great retention rate of $80.1 \%$ after 3000 cycles (Fig. 14c). Further enhancement in the specific surface area of GQDs can be achieved via $\mathrm{KOH}$ activation. Ultrafine pores and zig zag edges are introduced on GQDs by activation, resulting in a dramatic improvement $(200 \%)$ in specific capacitance $\left(236 \mathrm{~F} \mathrm{~g} \mathrm{~g}^{-1}\right)$, a value much higher than that of graphene $\left(172 \mathrm{~F} \mathrm{~g}^{-1}\right)$ activated under similar conditions [167]. 
(a)
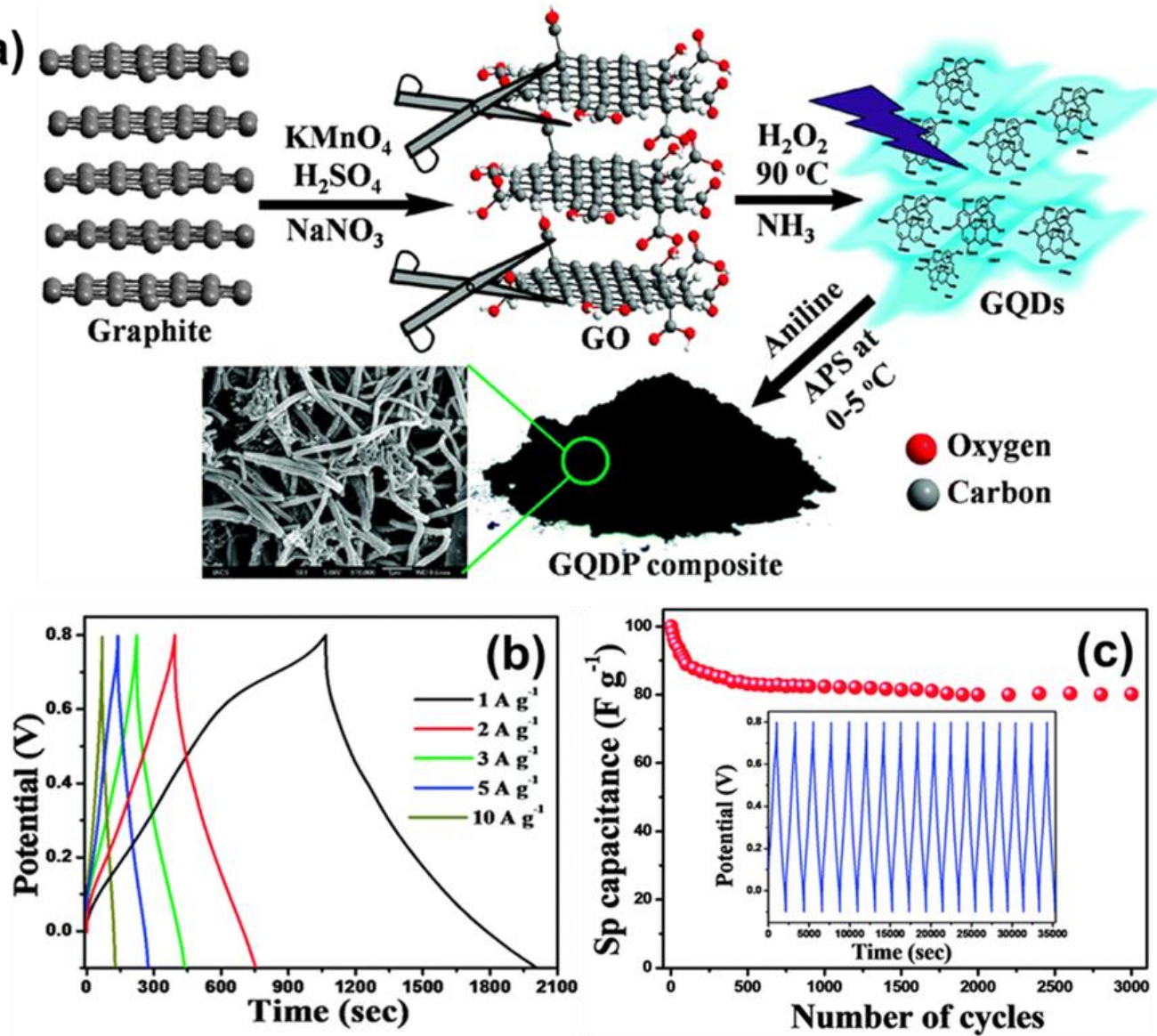

Fig. 14. (a) Schematic representation of the GQD/PANI composite preparation. (b) Galvanostatic charge discharge curves at various current densities, (c) life stability of GQD/PANI composite after 3000 cycles, inset is curve for 10 consecutive charge discharge cycles. Reprinted with permission from ref. [162]. Copyright (2015) Royal Society of Chemistry.

Recently, Mohammad et al. prepared GQDs grafted carbon fibre for high performance supercapacitors and observed a 5.5\% enhanced capacitance than that of bare carbon fibre. They demonstrated a high specific capacitance with retention rate of $97 \%$ after 5000 cycles [149]. Table 2 shows the comparison of the performance of supercapacitors based on GQDs and other graphene based materials. It is clearly observed that GQDs exhibit best performance (capacitance: $1044 \mathrm{~F} \mathrm{~g}^{-1}$ at $1 \mathrm{~A} \mathrm{~g}^{-1}$ [162] and $97.8 \%$ stability after 5000 cycles [149, 150]) among all graphene based materials. The plentiful ion-interacting edges, large specific surface area, plentiful accessible edges, defects, functional groups and chemical moiety sites associated with GQDs are responsible for their better capacitive performance.

\subsection{Batteries}

GQDs were first time utilized in Li-ion batteries (LiBs) by Fan and co-workers [147]. Fan et al. reported on the cathode material for $\mathrm{LiBs}$ by synthesizing a GQD-coated $\mathrm{VO}_{2}$-nanobelt arrays on 3-D graphene foam (Fig. 15a-c) [147]. A high specific capacitance of $421 \mathrm{~mA} \mathrm{~h} \mathrm{~g}^{-}$ 
1, 99\% coulombic efficiency, and high rate performance were obtained at a current density of $1 / 3 \mathrm{C}\left(1 \mathrm{C}=300 \mathrm{~mA} \mathrm{~g}^{-1}\right)$, outperforming $\mathrm{VO}_{2}$-nanobelt arrays without GQDs coating (Fig. $15 \mathrm{~d})$. Contrary to the poor stability of other $\mathrm{VO}_{2}$ based electrodes, the GQDs-anchored $\mathrm{VO}_{2}$ electrode show tremendous enhancement in its stability (a retention of 94\% capacity after 1500 cycles) [147]. This electrode also show good performance in the case of sodium ion batteries as a cathode material (a retention of $88 \%$ capacitance after 1500 cycles, and capacitance of 306 $\mathrm{mA} \mathrm{h} \mathrm{g}^{-1}$ at $1 / 3 \mathrm{C}$ ). At a high charge-discharge rate of $120 \mathrm{C}$, the electrode acquires a power density of $42 \mathrm{~kW} \mathrm{~kg}^{-1}$ with a good energy density of $4100 \mathrm{Wh} \mathrm{kg}^{-1}$ (Fig. 15e).

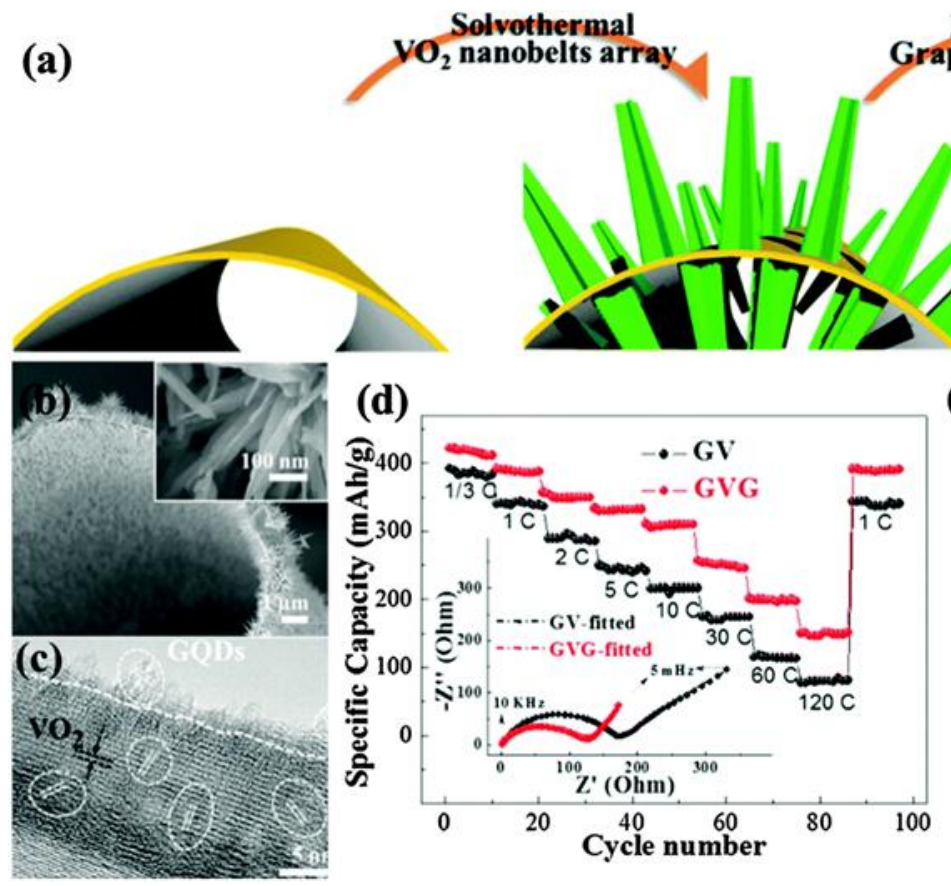

Electrophoresis raphene quantum dots

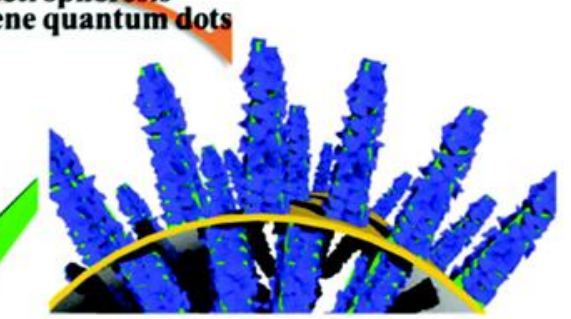

(e)

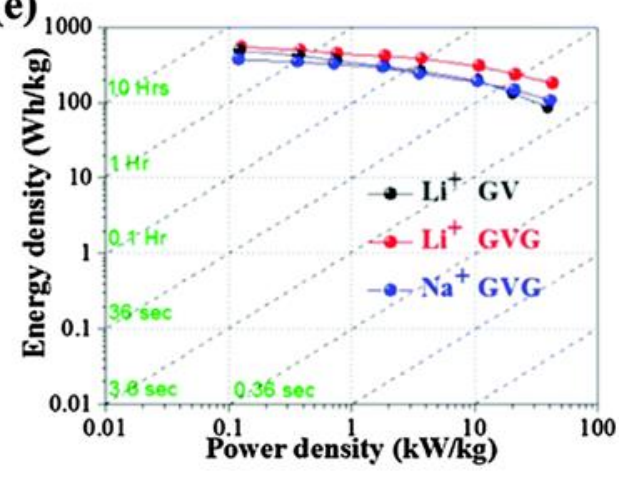

Fig. 15. Preparation of GQD-coated $V O_{2}$ nanobelt array supported on $3 D$ graphene $(G V G)$. (b, c) SEM and HRTEM images of the hybrid structure. (d) Rate performance of the as fabricated electrode with (GVG) and without (GV) GQD coating, inset in (d) is AC impedance plots. (e) Ragone plot of GVG electrode for Na and Li ion batteries. Reprinted with permission from ref. [147]. Copyright (2015) American Chemical Society.

In another study, the same group synthesized an anode material for LiBs by assembling $\mathrm{CuO}+\mathrm{Cu}+\mathrm{GQDs}$ triaxial nanowire arrays [168]. The schematic illustration of electrode fabrication is presented in Fig. 16a. Coating of GQDs outer layer results in the mossy surface of CCG nanowires (Fig. 16b) which indicates their enlarged surface area and enhanced connection sites for electrochemical reactions. Meanwhile, annealing of $\mathrm{CuO}$ nanowire in $\mathrm{Ar}$ $+\mathrm{H}_{2}$ converts its thin surface into a $\mathrm{Cu}$ metal and a smooth surfaced $\mathrm{CuO}+\mathrm{Cu}$ coaxial nanowire is obtained (Fig. 16c). Such a brilliant adjustment of GQDs in $\mathrm{CuO}$ nanowire array offers enhanced surface conductivity, improved stability and a high columbic efficiency (87\%) (Fig. 16d). As fabricated electrode demonstrates a high specific capacity of $780 \mathrm{~mA} \mathrm{~h} \mathrm{~g}^{-1}$ at $1 / 3 \mathrm{C}$ 
and $330 \mathrm{~mA} \mathrm{~h} \mathrm{~g}^{-1}$ at $4 \mathrm{C}$, outperforming $\mathrm{CuO}+\mathrm{Cu}$ electrode without GQDs (Fig. 16d) [168]. In both studies, improved performance of GQDs was based on several factors. First, the GQDs layer prevents the formation of a solid electrolyte interface film, which results in an enlarged Coulombic efficiency. Second, the conductivity and charge collection efficiency of the electrode is enhanced by ordered covering of GQDs over the surface of active materials, leading to a high rate performance. Third, a rough electrode surface conferred by the GQDs results in a large surface area leading to an improved metal ion storage. Lastly, GQDs act as a stabilizer to protect the electrode active materials from dissolution and/or agglomeration, leading to an improved cycling life of the electrode.
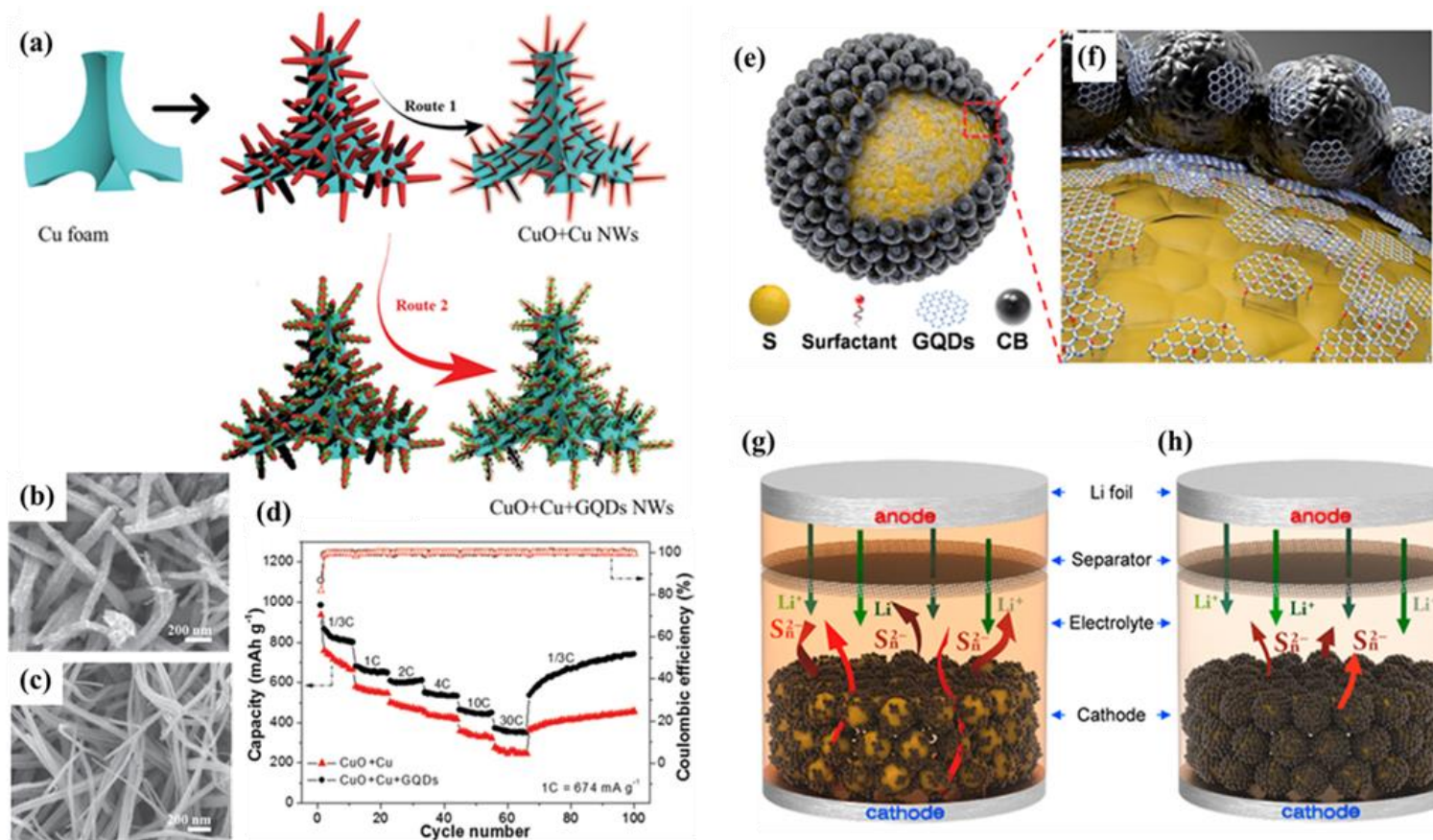

(g)

(h)

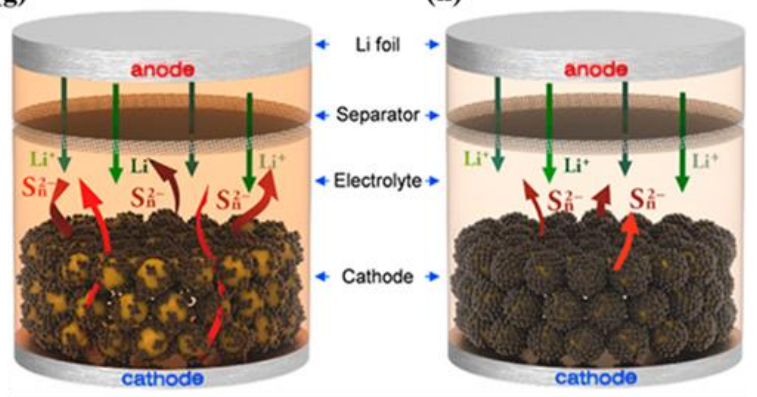

Fig. 16. (a) Schematic illustration of the synthesis process for CuO-based nanowire electrode. Route 1 is for the fabrication of $\mathrm{CuO}-\mathrm{Cu}(\mathrm{CC})$ core-shell nanowire and route 2 is for the preparation of $\mathrm{CuO}+\mathrm{Cu}+G Q D(C C G)$ triaxial nanowire. (b) SEM image of CCG triaxial nanowires, (c) CC core shell nanowires, (d) rate performance with Columbic efficiency of CCG and CC nanowire electrodes. Adopted and modified with permission from ref. [168]. Copyright (2015) Wiley Publishing Group. (e) Schematic diagram showing the structure and $(f)$ magnified structure of GQDs-sulphur/carbon black (GQDs-S/CB) composite. The sulfur (yellow ball) was wrapped with carbon-black (S/CB) and compactly covered with GQDs and CB (GQD$S / C B$ ). (g) Schematic arrangement of sulphur/carbon-black (S/CB) and (h) GQDs-S/CB utilized as a cathode in Li-S batteries. Adopted with permission from ref. [148]. Copyright (2016) Nature Publishing Group.

GQDs have also been employed in lithium-sulphur [148], Lithium-silicon [169], lithiumtitanate [170], and metal-air batteries [171]. Park et al. reported on the introduction of GQDs into the sulphur cathode of lithium-sulphur ( $\mathrm{Li}-\mathrm{S})$ batteries and demonstrated an enhanced 
sulphur-sulphide utilization, yielding high performance [148]. High structural integrity of sulphur-carbon composite electrode is induced by the oxygen rich functional groups of GQDs. Fig. 16e,f shows the schematic structure of GQDs-sulphur/carbon-black (GQDs-S/CB) composite. Fast charge transfer was acquired owning to the hierarchical structure of sulphurcarbon composite and the physiochemical properties of GQDs. The schematic diagram in Fig. 16g,h shows the conventional Li-S battery, in which lithium foil serve as an anode material and cathode is made up of sulphur/carbon-black (S/CB) or GQDs-S/CB composites. The cathode structure greatly influences the irreversible loss of high order polysulfides during cyclic charging-discharging process. The surface of sulphur particles is partially exposed in S/CB composite, as a result the polysulfides dissolved in solvent and changed the colour to orange Fig. 16g. The introduction of GQDs into the S/CB composite induces a densely packed structure and greatly enhances the performance of Li-S battery by preserving the high-order polysulfides (HOPSs) in the structure of GQDs-S/CB composite. At $0.5 \mathrm{C}$, the columbic efficiency of $100 \%$ and cyclic performance of $\sim 1000 \mathrm{~mA} \mathrm{~h} \mathrm{~g}^{-1}$ was maintained up to 100 cycles for GQDs-S/CB based battery. GQDs-S/CB electrode showed outstanding rate capability at $10 \mathrm{C}\left(540.17 \mathrm{~mA} \mathrm{~h} \mathrm{~g}^{-1}\right)$ as compared to $\mathrm{S} / \mathrm{CB}$ composite $\left(120.35 \mathrm{~mA} \mathrm{~h} \mathrm{~g}^{-1}\right)$. GQDs-S/CB showed extraordinary cyclic performance of $950 \mathrm{~mA} \mathrm{~h} \mathrm{~g}^{-1}$ even when electrode with high sulphur loading was prepared. These cyclic performance values are much higher than that of reported values for other sulphur/carbon composites [148]. 
Table 3. Comparison of the performance of Li-ion batteries based on GQDs and other graphene derivatives.

\begin{tabular}{|c|c|c|c|c|}
\hline Materials & Preparation approaches & Performance & Characteristics & Ref. \\
\hline $\begin{array}{c}\text { GQDs-VO } \\
\text { graphene }\end{array}$ & $\begin{array}{l}\text { Hydrothermal, solvothermal } \\
\text { processes and electrophoresis } \\
\text { deposition }\end{array}$ & $\begin{array}{c}\text { Capacitance: } 421 \mathrm{~mA} \mathrm{~h} \mathrm{~g}^{-1} \text { at } \\
1 / 3 \mathrm{C}, \\
\text { Stability: } 94 \% \text { after } 1500 \\
\text { cycles at } 60 \mathrm{C}\end{array}$ & $\begin{array}{l}\text { Thin, binder free, light } \\
\text { weight }\end{array}$ & [147] \\
\hline $\begin{array}{c}\mathrm{CuO}+\mathrm{Cu}+\mathrm{GQD} \\
\text { triaxial }\end{array}$ & $\begin{array}{l}\text { Hydrothermal, electrochemical } \\
\text { processes and electrophoresis } \\
\text { deposition }\end{array}$ & $\begin{array}{c}\text { Capacitance: } 780 \mathrm{~mA} \mathrm{~h} \mathrm{~g}^{-1} \text { at } \\
1 / 3 \mathrm{C}\end{array}$ & $\begin{array}{l}\text { Binder free, additive } \\
\text { free }\end{array}$ & [168] \\
\hline GQDs-S/CB & $\begin{array}{l}\text { Refluxing, chemical reduction, } \\
\text { high temperature stirring }\end{array}$ & $\begin{array}{c}\text { Capacitance: } 1000 \mathrm{~mA} \mathrm{~h} \mathrm{~g}^{-1} \text { at } \\
0.5 \mathrm{C}\end{array}$ & Low cost, flexible & [148] \\
\hline PF-GQD@SiNP & $\begin{array}{l}\text { Hydrothermal treatment, thermal } \\
\text { annealing, stirring }\end{array}$ & $\begin{array}{l}\text { Capacitance: } 4066 \mathrm{~mA} \mathrm{~h} \mathrm{~g}^{-1} \text { at } \\
50 \mathrm{~mA} \mathrm{~g}^{-1}\end{array}$ & $\begin{array}{l}\text { Low cost, eco-friendly, } \\
\text { binder free }\end{array}$ & [169] \\
\hline $\begin{array}{l}\text { LTO decorated by } \\
\text { GO and } \\
\text { LMO/MWNT yarn }\end{array}$ & Hydrothermal, rolled approach & $\begin{array}{l}\text { Energy density: } 27 \mathrm{~W} \mathrm{~kg}^{-1} \\
\text { power density: } 880 \mathrm{~W} \mathrm{~kg}^{-1}\end{array}$ & Low weight, flexible & [172] \\
\hline $\begin{array}{c}\text { Graphene on } \\
\text { graphene hybrid film }\end{array}$ & CVD, GO reduction & $\begin{array}{l}\text { Capacitance: } 770 \mathrm{~mA} \mathrm{~h} \mathrm{~g}^{-1} \text { at } \\
\qquad 372 \mathrm{~mA} \mathrm{~g}^{-1}\end{array}$ & $\begin{array}{l}\text { Flexible, all graphene, } \\
\text { binder free }\end{array}$ & [173] \\
\hline $\begin{array}{l}\mathrm{SnO}_{2} \text {-graphene } \\
\text { composite }\end{array}$ & Self-assembly & $\begin{array}{c}\text { Capacitance: } 625 \mathrm{~mA} \mathrm{~h} \mathrm{~g}^{-1} \text { at } \\
10 \mathrm{~mA} \mathrm{~g}^{-1}, 760 \mathrm{~mA} \mathrm{~h} \mathrm{~g}^{-1} \text { at } 8 \\
\mathrm{~mA} \mathrm{~g}^{-1}\end{array}$ & $\begin{array}{l}\text { Binder free, flexible, } \\
\text { additive free }\end{array}$ & [174] \\
\hline
\end{tabular}

GQDs have been utilized in lithium-silicon batteries for the passivation of silicon, which is very promising anode material for LIBs but faces a challenge of large volume variation and rapid capacity loss during charging-discharging process. Lijuan et al. coated a layer of phenylalanine-functionalized GQDs on the silicon nanoparticles to improve the electrical conductivity and prevent direct contact of electrolyte with silicon [169]. As a result, they acquired a stable and high capacitance of $3796 \mathrm{~mA} \mathrm{~h} \mathrm{~g}^{-1}$ at $100 \mathrm{~mA} \mathrm{~g}^{-1}$ with $76 \%$ retention (3068 $\mathrm{mA} \mathrm{h} \mathrm{g}^{-1}$ ) after 100 cycles [169]. The incorporation of $\mathrm{N}$ and $\mathrm{S}$ co-doped GQDs onto the titanate anode of lithium-titanate batteries could enhance the power density and rate performance due to enhanced electron transfer and lithium storage capacity [170]. LIBs based on GQDs show superior capacitive performance (4066 $\mathrm{mA} \mathrm{h} \mathrm{g}^{-1}$ ) [169] over other graphene based materials (up to $770 \mathrm{~mA} \mathrm{~h} \mathrm{~g}^{-1}$ ) [173] (Table 3).

\subsection{Photovoltaics}

Owning to the extraordinary electronic/optical properties, GQDs may be implemented in various components of photovoltaics, such as sensitizers, activators, active layers, catalysts for the counter electrode. Gao et al. used GQDs as active layer to fabricate Si/GQD heterojunction solar cell [175]. The GQDs active layer suppresses charge recombination and indorses electronhole separation (Fig. 17a). The photo conversion efficiency (PCE) of $6.6 \%$ was displayed by 
the cell, much higher than that of undecorated Si based cell (2.26\%) or the one with GO sheets acting as active layers (3.99\%). Dutta et al. synthesized GQD/ZnO nanowire heterojunction solar cell which showed the current density (Jsc) of 75 times higher than that of bare $\mathrm{ZnO}$ nanowire based cell [176]. However, a low PCE was obtained due to the limited GQDs connections with the hole-transport layer (HTL) causing a low hole-collection efficiency. Using hot injection approach, Tavakoli and co-workers synthesized PbS QD/GQD core/shell hybrids (Fig. 17b) [177]. In contrast with commonly utilized capping molecules, the ultrathin layer of GQDs makes incomplete surface passivation of PbS QDs, declines the number of trap states and enhances faster extraction of charge carriers. An improved current density (13.4 mA $\left.\mathrm{cm}^{-2}\right)$, PCE (3.6\%) and open voltage (0.58 V) was obtained for solar cell with PbS QD/GQDs active layers than that of organic molecules capped PbS QDs based devices (Fig. 17b) [177]. Cd doping of PbS QDs can further improve the PCE of PbS QD/GQD cell by 4.1\%. Qu et al. prepared polymer based bulk-heterojunction (BHJ) solar cell with a structure of ITO/PEDOT:PSS/P3HT:GQD/AL [90]. Plentiful p-n junctions formed inside the P3HT:GQD active layer promote the alienation of photogenerated excitations and electron transfer. Ideally, the open circuit voltage can be improved from $0.5 \mathrm{~V}$ to $0.8 \mathrm{~V}$ by introduction of GQDs. A PCE of $1.28 \%$ was obtained from actual device with $J_{\mathrm{sc}}$ of $6.33 \mathrm{~mA} \mathrm{~cm} \mathrm{~cm}^{-2}$ and a $V_{\mathrm{oc}}$ of $0.67 \mathrm{~V}$. The charge carrier concentration of the polymer device can be improved by $30 \%$ with the addition of Cl-doped GQDs to the P3HT active layer (Fig. 17c) [178]. 

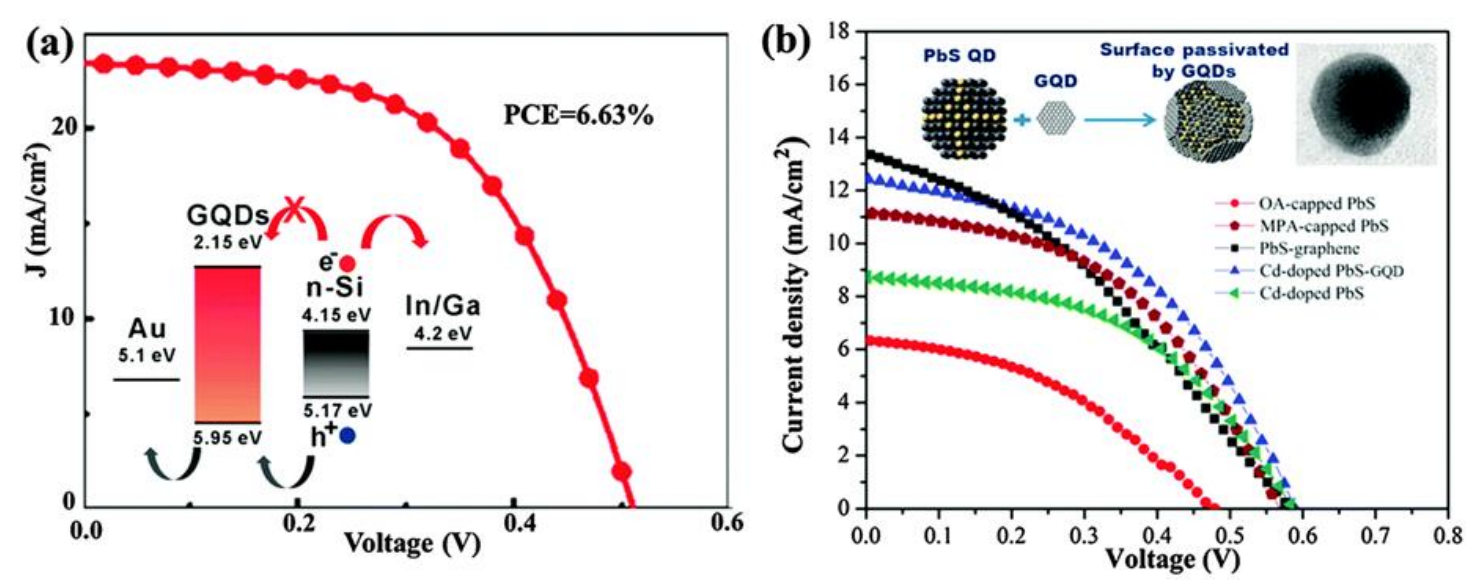

(c)

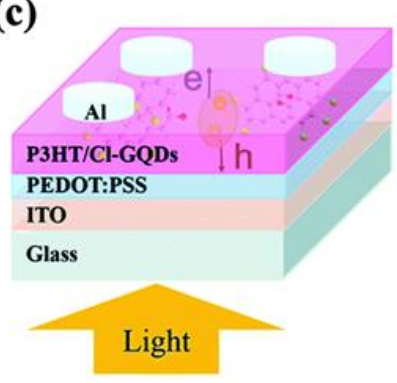

(e)

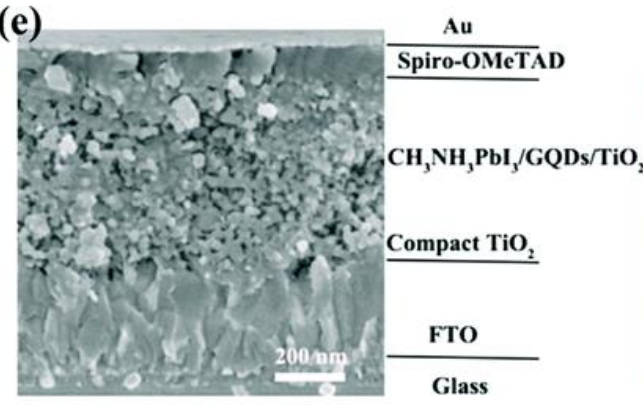

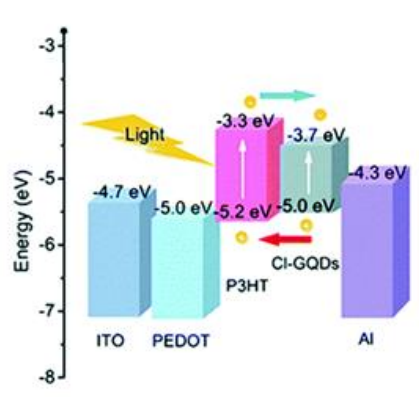

(d)

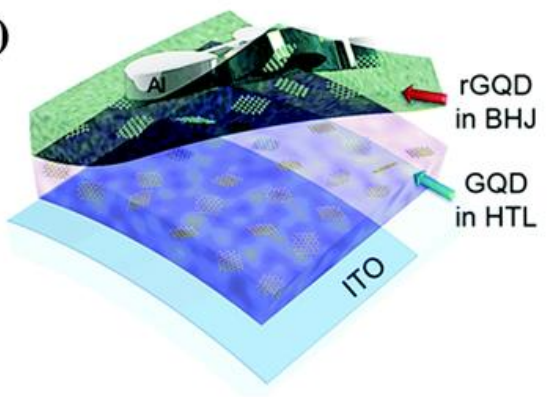

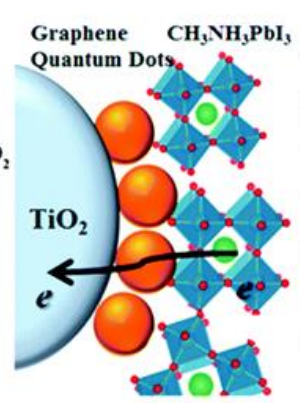

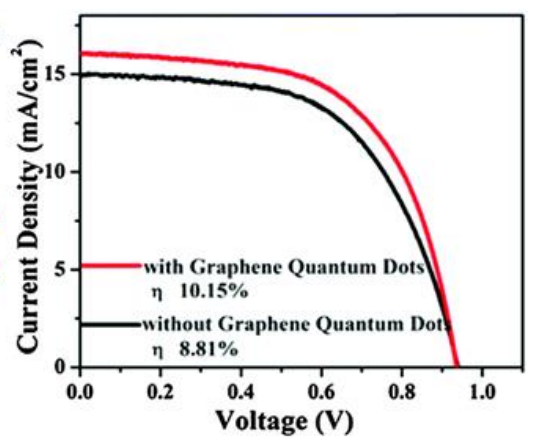

Fig. 17. (a) CH3-SI/GQD heterojunction solar cell showing J-V curve at Am1.5G (the inset shows its energy band diagram). Adopted and modified with permission from ref. [175]. Copyright (2014) American Chemical Society. (b) A schematic diagram of PbS QDs surface passivated by GQDs and PbS based solar cells' J-V curves under Am1.5G. Reprinted with permission from ref. [177]. Copyright (2014) American Chemical Society. (c) Schematic of a photovoltaic device based on GQD-Cl hybrid and its working mechanism. Reprinted with permission from ref. [178]. Copyright (2015) Royal Society of Chemistry. (d) Illustration of a photovoltaic device based on GQDs in hole-transport layer (HTL) and hydrothermally reduced GQDs in the BHJ layer. Reprinted with permission from ref. [141]. Copyright (2015) Nature Publishing group. (e) SEM image (cross sectional view) of perovskite solar cell on left side, illustration of its working mechanism in middle, and J-V curves of the cell without or with GQD on right. Adopted with permission from ref. [179]. Copyright (2014) American Chemical Society.

Gupta and co-workers developed a solar cell using aniline functionalized GQDs as a filler of P3HT and the cell configuration consist of ITO/PEDOT:PSS/P3HT:ANI-GQDs/LiF/Al [180]. The device demonstrated a superior PCE (1.14\%) than the control device with an active layer of P3HT:ANI-graphene sheet (PCE: 0.65\%). The rough structure of P3HT:ANIgraphene film due to large sized graphene sheets induces extra phase separation surpassing the 
diffusion length of excitons, resulting in a poorer performance [181]. Kim et al. developed a BHJ solar device based on PTB7:PC 71 BM active layer containing GQDs with various number of oxygenated groups [181]. The oxygen functional groups on the surface of GQDs were found to improve the optical absorptivity of device leading to a significantly enhanced Jsc, while the superior conductivity of less-oxidized GQDs resulting in competent charge carrier extraction can improve the fill factors (FFs). The balance between these two features gives a highest PCE of $7.6 \%$. Elsewhere, they reported that with the addition of hydrophilic GQDs onto the PEDOT:PSS hole transporting layer, the Jsc of the BHJ solar cell can be enhanced from 15.6 $\mathrm{mA} \mathrm{cm}{ }^{-2}$ to $17.3 \mathrm{~mA} \mathrm{~cm}^{-2}$. This improvement can be assigned to the enhanced conductance of charge carriers in the ITO/PEDOT:PSS due to the strong interaction between GQDs having a negative charge and PEDOT with a positive charge [141]. In order to understand the synergistic effects, hydrophilic GQDs were introduced into PEDOT:PSS HTL layer and hydrothermally reduced hydrophobic rGQDs were incorporated into PTB7:PC 71 BMBHJ layer (Fig. 17d), and a greatly enhanced PCE of $8.67 \%$ have been achieved. Using chemical-group-free GQDs, Yan and co-workers tried to sensitize $\mathrm{TiO}_{2}$ photoanode for solar cell [94]. However, Jsc magnitude of the cell was decreased by two order than that of dye-sensitized solar cells (DSSC) due to the poor binding affinity of GQDs with $\mathrm{TiO}_{2}$. If the GQDs with oxygen groups are used, the performance could be considerably improved because these GQDs can interact significantly with $\mathrm{TiO}_{2}[182,183]$. When N719 dye and GQDs are used together as sensitizer and cosensitizer in $\mathrm{TiO}_{2}$ photoanodes, an uplift of PCE from 4.9 to $6.1 \%$ and rise of Jsc from 9.72 to $14.07 \mathrm{~mA} \mathrm{~cm}^{-2}$ is observed [184]. Mihalache et al. reported similar findings of increase in Jsc and PCE for DSSC through N-doped GQDs as co-sensitizer along with N3 Ru-Dye [185]. The improved performance of DSSC device can be attributed to the improved charge separation, overlapped PL spectrum of GQDs with adsorption spectrum of $\mathrm{N}_{3} \mathrm{Ru}-$ dye, and suppressed electron recombination to the redox couple in the electrolyte. Lee et al. increased the amount of light employed by DSSCs by depositing GQDs onto $\mathrm{TiO}_{2}$ with upconversion PL and observed an increase of PCE from 7.28 to $9.2 \%$ [186]. Chen et al. introduced GQDs to the polypyrrole counter electrode to make it highly porous and enhanced PCE of the DSSC [187]. In a recent study ultrathin layer of GQDs was introduced to a perovskite solar device with a structure of $\mathrm{CH}_{3} \mathrm{NH}_{3} \mathrm{PbI}_{3} / \mathrm{GQDs} / \mathrm{TiO}_{2}$, and an improvement in PCE from 8.81 to $10.15 \%$ and Jsc from 17.07 to $15.34 \mathrm{~mA} \mathrm{~cm}^{-2}$ was obtained (Fig. 17e) [179]. This enhanced performance is attributed to the faster electron extraction, which guarantees improved photon-to-current conversion in visible region, and $75 \%$ PL quenching of the perovskite- $\mathrm{TiO}_{2}$ film. 
Table 4. A comparison of the preparation approaches, performance and characteristics of the photovoltaic devices based on GQDs and other graphene derivatives.

\begin{tabular}{|c|c|c|c|c|}
\hline Materials & $\begin{array}{l}\text { Preparation } \\
\text { approaches }\end{array}$ & Performance & Characteristics & Ref. \\
\hline $\begin{array}{c}\text { Aniline- } \\
\text { functionalized } \\
\text { GQDs and P3HT }\end{array}$ & Sin casting & $\begin{array}{l}\text { Power conversion efficiency,: } 1.14 \% \text {, } \\
\text { density of short circuit: } 6.33 \mathrm{~mA} \mathrm{~cm}{ }^{-2} \text {, } \\
\text { open circuit voltage: } 0.67 \mathrm{~V} \text {, fill } \\
\text { factor: } 0.53\end{array}$ & $\begin{array}{c}\text { Heterogeneous nanoscale phase, } \\
\text { electron acceptor }\end{array}$ & [180] \\
\hline GQDs & $\begin{array}{l}\text { Electrochemical } \\
\text { corrosion } \\
\text { technique }\end{array}$ & $\begin{array}{l}\text { Power conversion efficiency,: } 1.28 \% \text {, } \\
\text { density of short circuit: } 6.33 \mathrm{~mA} \mathrm{~cm}{ }^{-2} \text {, } \\
\text { open circuit voltage: } 0.67 \mathrm{~V}\end{array}$ & $\begin{array}{l}\text { High electron mobility, electron } \\
\text { acceptor }\end{array}$ & [90] \\
\hline Colloidal GQDs & $\begin{array}{l}\text { Solution synthesis } \\
\text { method }\end{array}$ & $\begin{array}{l}\text { Faster component: } 18 \pm 3 \text { ps, slower } \\
\text { component: } 100 \text { ps to nanoseconds }\end{array}$ & $\begin{array}{l}\text { exciton generator, Improved } \\
\text { efficiency for hot electron } \\
\text { extraction }\end{array}$ & [188] \\
\hline $\begin{array}{l}\text { GQDs and } \mathrm{TiO}_{2} \\
\text { composite }\end{array}$ & $\begin{array}{l}\text { Chemically } \\
\text { anchored } \\
\text { approach }\end{array}$ & $\begin{array}{l}\text { The injection of electron from GQD to } \\
\text { TiO2 conduction band: < } 15 \text { fs, quick } \\
\text { recombination of exciton: } 0.5-2 \mathrm{ps,} \\
\text { charge recombination: } 80-130 \mathrm{fs}\end{array}$ & $\begin{array}{l}\text { Ultrafast electron injection, hot } \\
\text { carrier chromophores }\end{array}$ & [183] \\
\hline $\begin{array}{c}\text { Monodispersed } \\
\text { GQDs }\end{array}$ & $\begin{array}{l}\text { Solution synthesis } \\
\text { method }\end{array}$ & $\begin{array}{c}\text { Emitting both fluorescence and } \\
\text { phosphorescence, relaxing into triplet } \\
\text { states }\end{array}$ & $\begin{array}{l}\text { Triplet excitons, long lifetimes, } \\
\text { exciton generator }\end{array}$ & [189] \\
\hline $\begin{array}{l}\text { Graphene and } \mathrm{Pt} \\
\text { composite fibres }\end{array}$ & $\begin{array}{l}\text { Spinning and } \\
\text { electrodeposition }\end{array}$ & $\begin{array}{l}\text { short circuit density: } 12.67-17.11 \mathrm{~mA} \\
\mathrm{~cm}^{-2} \text {, open circuit voltage: } 0.73 \mathrm{~V} \text {, fill } \\
\text { factor: } 0.42-0.67\end{array}$ & $\begin{array}{l}\text { Counter electrode, light weight, } \\
\text { wearable, flexible }\end{array}$ & {$[190]$} \\
\hline $\begin{array}{l}\text { Graphene/ CdS } \\
\text { quantum dot } \\
\text { composite }\end{array}$ & $\begin{array}{l}\text { Layer by layer } \\
\text { assembly }\end{array}$ & $\begin{array}{l}\text { Photoresponse: } 1.08 \mathrm{~mA} \mathrm{~cm}^{-2} \text { under } \\
100 \mathrm{~mW} \mathrm{~cm}{ }^{-2} \text {, quantum efficiency: } \\
16 \% \text { at } 400 \mathrm{~nm}\end{array}$ & $\begin{array}{l}\text { Balanced charge transfer, } \\
\text { graphene electron acceptor }\end{array}$ & [191] \\
\hline $\begin{array}{l}\text { Graphene/CNT/ } \\
\text { Pt composite } \\
\text { fibres }\end{array}$ & $\begin{array}{l}\text { Biscrolling } \\
\text { approach, } \\
\text { electrodeposition }\end{array}$ & $\begin{array}{c}\text { Capacitance of two fibres intertwined: } \\
31.50 \mathrm{~F} \mathrm{~g}^{-1} \text {, conversion efficiency: } \\
8.36 \%\end{array}$ & $\begin{array}{l}\text { Counter electrode, wearable, } \\
\text { flexible, miniature devices }\end{array}$ & [192] \\
\hline
\end{tabular}

Phosphorene is desirable for photoelectronic applications because of its bipolar characteristics, high hole mobility and narrow bandgap ( 0.3 to $1.5 \mathrm{eV}$ based on the number of layers) [193]. Deng et al. prepared a heterojunction between n-type monolayer $\mathrm{MoS}_{2}$ and ptype few layer phosphorene, fabricating a p-n diode for photovoltaic energy conversion with PCE of $0.3 \%$ [194]. The theoretical predictions indicate that PCE of a p-n diode can be increased to $18 \%$ by reducing the thickness of phosphorene to only two layers [193]. Based on the bipolar characteristic of few layer phosphorene, Buscema et al. utilized single phosphorene sheet to fabricate a p-n heterojunction with 2 regions differently biased by $2 \mathrm{~h}$ BN dielectric gates [195]. As a result, the photovoltaic effect can be extended to near-IR region. 
The electrical band gap between graphene and TMDs is filled by phosphorene. Thus the application gap between GQDs and TMD-QDs shall be filled by phosphorene QDs. A large number of photovoltaic devices based on GQDs have been synthesized which outperform other graphene based materials (Table 4).

\section{Challenges and perspectives}

Biomass is a sustainable and rich source of carbon production. For the proficient utilization of carbon resources, it is necessary to understand the carbon chemistry and factors influencing its properties. This review highlighted the novel research on biomass derived GQDs and their potential application in various fields. GQDs derived from biomass waste are emergent zero dimensional materials which cover an extensive range of intriguing properties (e.g. chemical, electrochemical, optical, catalytic, electronic, etc.). Owning to the lower dimension of GQDs, they often achieve surplus advantages over their 2D counter parts. First, the properties of GQDs are tunable with more sensitivity by size, thickness, chemical functionalities, edge configuration, thickness, defects, or heteroatom dopants. This could help rise of novel properties for unique applications. Second, minute perturbation or interactions have significant effect on their properties. This is demanding for the development of high sensitivity sensors. In addition, these GQDs are often easier to functionalize with other nanomaterials to acquire composite properties. Moreover, due to better solubility they have better responsiveness for solution based processes. Finally, tiny size is the key benefit for bio-imaging purpose of GQDs because these are used as fluorescent tags on molecular targets and the function and dynamics of targets may be changed if large tags are used.

Accompanied with a vast range of excellent properties, GQDs thus show high promise for extensive series of novel applications. Although only a few applications of biomass derived GQDs and energy applications of GQDs in general are focused in this article, GQDs are also highly promising for catalysis, drug delivery, bioimaging, photodynamic therapy, optical sensing, electrochemical sensors, optoelectronics, display, etc.[7, 83, 89, 196-208]. Recently, Zheng et al. comprehensively reviewed the biological applications of GQDs [53]. Particularly to be revealed, owning to the numerous key features (e.g. biocompatibility, photostability, nontoxicity, etc.) GQDs are superior to widely used conventional semiconductor QDs and organic fluorophores for various biological applications, such as bioimaging [53, 69, 70]. Using insulin-functionalized GQDs, for example, Zheng et al. visualized the distribution and dynamics of insulin receptors in live adipocytes [209]. 
In spite of the emerging recent progress, research on biomass derived GQDs is still on its early phase and many challenges need to be tackled. Although biomass could be a cheap and renewable resource but the total cost of production might be higher as compared to other precursors such as graphite, coal, carbon fibres, etc. Due to high sensitivity of GQDs towards size, thickness, edge engineering, heteroatom doping and chemical functionalization, developing advanced preparation methods are highly desired for the precise control over these parameters. Precursor employed has a significant effect on the final properties and engineering control of GQDs. Thus, controlling the properties of biomass derived GQDs are comparatively difficult due to inherent nature of the feedstock. Therefore, advanced synthesis approaches are highly demanded for getting a precise control over property-application relationship. Nonetheless, often this aim has to be well-adjusted by the demands for low cost and large scale productions. On this path, several researchers tried to develop large scale production of GQDs from biomass, however, still the actual amount is in grams if not in milligrams [73, 74]. Since biomass is a renewable and abundant available source, scalable and cheap synthesis approach using biomass precursor will find high promise for commercialization. The basic understanding of the optical, electronic, catalytic and electrochemical properties of the biomass derived GQDs is still very limited and sometimes even controversial due to their large heterogeneity of the precursor material. Careful consideration of chemical and electrochemical stability is required for the practical use of GQDs. But the studies in this respect are limited. Compared with the conventional fluorophores, relatively low quantum yield and broad emission band are the problems associated with the GQDs based fluorescent probes. The former issue can be resolved by reduction in the surface traps and by introduction of dopants, passivation layers, or chemical functionalities. The later one can be tackled by producing GQDs with narrow property distribution. We believe this article will help stimulate the progress of this emerging and fascinating research field.

\section{Acknowledgements}

The authors would like to thank Faculty of Science, Agriculture \& Engineering (SAgE), School of Engineering, and International Fund Partnership Newcastle University for their financial support. 


\section{References}

[1] S. Franco, V.R. Mandla, K. Ram Mohan Rao, Urbanization, energy consumption and emissions in the Indian context A review, Renewable Sustainable Energy Rev. 71 (2017) 898907.

[2] H. Alam, S. Ramakrishna, A review on the enhancement of figure of merit from bulk to nano-thermoelectric materials, Nano Energy 2(2) (2013) 190-212.

[3] J. Goldemberg, T.B. Johansson, A.K.N. Reddy, R.H. Williams, Energy for a sustainable world, Wiley New York, 1988.

[4] B. Hu, K. Wang, L. Wu, S.-H. Yu, M. Antonietti, M.-M. Titirici, Engineering Carbon Materials from the Hydrothermal Carbonization Process of Biomass, Adv. Mater. 22(7) (2010) 813-828.

[5] J. Deng, M. Li, Y. Wang, Biomass-derived carbon: Synthesis and applications in energy storage and conversion, Green Chem. 18(18) (2016) 4824-4854.

[6] R. Ye, C. Xiang, J. Lin, Z. Peng, K. Huang, Z. Yan, N.P. Cook, E.L.G. Samuel, C.-C. Hwang, G. Ruan, Coal as an abundant source of graphene quantum dots, Nat. Commun. 4 (2013).

[7] J. Shen, Y. Zhu, X. Yang, C. Li, Graphene quantum dots: emergent nanolights for bioimaging, sensors, catalysis and photovoltaic devices, Chem. Commun. 48(31) (2012) 36863699.

[8] W.H. Suh, K.S. Suslick, G.D. Stucky, Y.-H. Suh, Nanotechnology, nanotoxicology, and neuroscience, Prog. Neurobiol. 87(3) (2009) 133-170.

[9] H.W. Kroto, J.R. Heath, S.C. O'Brien, R.F. Curl, R.E. Smalley, C 60: buckminsterfullerene, Nature 318(6042) (1985) 162-163.

[10] M.M. Titirici, A. Thomas, M. Antonietti, Replication and coating of silica templates by hydrothermal carbonization, Adv. Funct. Mater. 17(6) (2007) 1010-1018.

[11] S.-H. Yu, X. Cui, L.L. Li, K. Li, B. Yu, M. Antonietti, H. Cölfen, From starch to metal/carbon hybrid nanostructures: hydrothermal metal-catalyzed carbonization, Adv. Mater. 16(18) (2004) 1636-1640.

[12] I. Balcke, R. Kroepke, S. Schulz, Cosmetic or dermatological preparation for application on wet skin, Google Patents, 2017.

[13] S. Iijima, T. Ichihashi, Single-shell carbon nanotubes of 1-nm diameter, Nature 363(6430) (1993) 603-605.

[14] X. Yao, Y. Zhao, Three-Dimensional Porous Graphene Networks and Hybrids for Lithium-Ion Batteries and Supercapacitors, Chem 2(2) (2017) 171-200.

[15] F. Su, Z. Tian, C.K. Poh, Z. Wang, S.H. Lim, Z. Liu, J. Lin, Pt nanoparticles supported on nitrogen-doped porous carbon nanospheres as an electrocatalyst for fuel cells, Chem. Mater. 22(3) (2009) 832-839.

[16] P. Chingombe, B. Saha, R.J. Wakeman, Surface modification and characterisation of a coal-based activated carbon, Carbon 43(15) (2005) 3132-3143.

[17] T. Kawano, M. Kubota, M.S. Onyango, F. Watanabe, H. Matsuda, Preparation of activated carbon from petroleum coke by $\mathrm{KOH}$ chemical activation for adsorption heat pump, Appl. Therm. Eng. 28(8) (2008) 865-871.

[18] X. Xie, B. Goodell, Thermal degradation and conversion of plant biomass into high value carbon products, ACS Symp. Ser., 2014, pp. 147-158.

[19] P. McKendry, Energy production from biomass (part 1): overview of biomass, Bioresour. Technol. 83(1) (2002) 37-46.

[20] N.J. Themelis, L. Arsova, Calculating Tons To Composting In The US, Bio Cycle 56 (2015) 27. 
[21] L.D. Schmidt, P.J. Dauenhauer, Chemical engineering: hybrid routes to biofuels, Nature 447(7147) (2007) 914-915.

[22] D. Tilman, J. Hill, C. Lehman, Carbon-negative biofuels from low-input high-diversity grassland biomass, Science 314(5805) (2006) 1598-1600.

[23] A. Jain, R. Balasubramanian, M.P. Srinivasan, Hydrothermal conversion of biomass waste to activated carbon with high porosity: A review, Chem. Eng. J. 283 (2016) 789-805.

[24] F. Shafizadeh, Introduction to pyrolysis of biomass, J. Anal. Appl. Pyrolysis 3(4) (1982) 283-305.

[25] J.A. Libra, K.S. Ro, C. Kammann, A. Funke, N.D. Berge, Y. Neubauer, M.-M. Titirici, C. Fühner, O. Bens, J. Kern, Hydrothermal carbonization of biomass residuals: a comparative review of the chemistry, processes and applications of wet and dry pyrolysis, Biofuels 2(1) (2011) 71-106.

[26] P.T. Williams, S. Besler, The influence of temperature and heating rate on the slow pyrolysis of biomass, Renewable energy 7(3) (1996) 233-250.

[27] F. Ronsse, S. Van Hecke, D. Dickinson, W. Prins, Production and characterization of slow pyrolysis biochar: influence of feedstock type and pyrolysis conditions, Gcb Bioenergy 5(2) (2013) 104-115.

[28] A.C. Lua, T. Yang, J. Guo, Effects of pyrolysis conditions on the properties of activated carbons prepared from pistachio-nut shells, J. Anal. Appl. Pyrolysis 72(2) (2004) 279-287.

[29] M. Ringer, V. Putsche, J. Scahill, Large-scale pyrolysis oil, Assessment (2006).

[30] A. Gani, I. Naruse, Effect of cellulose and lignin content on pyrolysis and combustion characteristics for several types of biomass, Renewable Energy 32(4) (2007) 649-661.

[31] J.I. Montoya, F. Chejne-Janna, M. Garcia-Pérez, Fast pyrolysis of biomass: A review of relevant aspects.: Part I: Parametric study, Dyna 82(192) (2015) 239-248.

[32] A.S. Kalgo, The development and optimisation of a fast pyrolysis process for bio-oil production, (2011).

[33] Y.-C. Lin, J. Cho, G.A. Tompsett, P.R. Westmoreland, G.W. Huber, Kinetics and mechanism of cellulose pyrolysis, J. Phys. Chem. C 113(46) (2009) 20097-20107.

[34] B.D. Ratner, A.S. Hoffman, F.J. Schoen, J.E. Lemons, Biomaterials science: an introduction to materials in medicine, Academic press2004.

[35] A.V. Bridgwater, Review of fast pyrolysis of biomass and product upgrading, Biomass Bioenergy 38 (2012) 68-94.

[36] S. Guo, X. Dong, T. Wu, C. Zhu, Influence of reaction conditions and feedstock on hydrochar properties, Energy Convers. Manage. 123 (2016) 95-103.

[37] S.K. Hoekman, A. Broch, C. Robbins, Hydrothermal carbonization (HTC) of lignocellulosic biomass, Energy \& Fuels 25(4) (2011) 1802-1810.

[38] M. Toufiq Reza, A. Freitas, X. Yang, S. Hiibel, H. Lin, C.J. Coronella, Hydrothermal carbonization (HTC) of cow manure: Carbon and nitrogen distributions in HTC products, Environ. Prog. Sustainable Energy 35(4) (2016) 1002-1011.

[39] A. Funke, F. Ziegler, Hydrothermal carbonization of biomass: a summary and discussion of chemical mechanisms for process engineering, Biofuels, Bioprod. Biorefin. 4(2) (2010) 160177.

[40] T. Hirose, T. Fujino, T. Fan, H. Endo, T. Okabe, M. Yoshimura, Effect of carbonization temperature on the structural changes of woodceramics impregnated with liquefied wood, Carbon 40(5) (2002) 761-765.

[41] F. Salvador, M.J. Sánchez-Montero, C. Izquierdo, C/H2O reaction under supercritical conditions and their repercussions in the preparation of activated carbon, J. Phys. Chem. C 111(37) (2007) 14011-14020.

[42] M.-M. Titirici, M. Antonietti, Chemistry and materials options of sustainable carbon materials made by hydrothermal carbonization, Chem. Soc. Rev. 39(1) (2010) 103-116. 
[43] Y. Yang, J. Cui, M. Zheng, C. Hu, S. Tan, Y. Xiao, Q. Yang, Y. Liu, One-step synthesis of amino-functionalized fluorescent carbon nanoparticles by hydrothermal carbonization of chitosan, Chem. Commun. 48(3) (2012) 380-382.

[44] M. Sevilla, A.B. Fuertes, The production of carbon materials by hydrothermal carbonization of cellulose, Carbon 47(9) (2009) 2281-2289.

[45] B. Jia, L. Gao, J. Sun, Self-assembly of magnetite beads along multiwalled carbon nanotubes via a simple hydrothermal process, Carbon 45(7) (2007) 1476-1481.

[46] K. Tekin, S. Karagöz, S. Bektaş, A review of hydrothermal biomass processing, Renewable Sustainable Energy Rev. 40 (2014) 673-687.

[47] M. Sevilla, A.B. Fuertes, Chemical and structural properties of carbonaceous products obtained by hydrothermal carbonization of saccharides, Chem. - Eur. J. 15(16) (2009) 41954203.

[48] Y. Shen, S. Yu, S. Ge, X. Chen, X. Ge, M. Chen, Hydrothermal carbonization of medical wastes and lignocellulosic biomass for solid fuel production from lab-scale to pilot-scale, Energy 118 (2017) 312-323.

[49] Q. Wang, H. Li, L. Chen, X. Huang, Monodispersed hard carbon spherules with uniform nanopores, Carbon 39(14) (2001) 2211-2214.

[50] X. Sun, Y. Li, Colloidal carbon spheres and their core/shell structures with noble-metal nanoparticles, Angew. Chem. Int. Ed. 43(5) (2004) 597-601.

[51] M. Owsianiak, M.W. Ryberg, M. Renz, M. Hitzl, M.Z. Hauschild, Environmental performance of hydrothermal carbonization of four wet biomass waste streams at industryrelevant scales, ACS Sustainable Chem. Eng. 4(12) (2016) 6783-6791.

[52] L. Wei, M. Sevilla, A.B. Fuertes, R. Mokaya, G. Yushin, Hydrothermal Carbonization of Abundant Renewable Natural Organic Chemicals for High-Performance Supercapacitor Electrodes, Adv. Energy Mater. 1(3) (2011) 356-361.

[53] X.T. Zheng, A. Ananthanarayanan, K.Q. Luo, P. Chen, Glowing graphene quantum dots and carbon dots: properties, syntheses, and biological applications, Small 11(14) (2015) 16201636.

[54] Ç.Ö. Girit, J.C. Meyer, R. Erni, M.D. Rossell, C. Kisielowski, L. Yang, C.-H. Park, M.F. Crommie, M.L. Cohen, S.G. Louie, A. Zettl, Graphene at the Edge: Stability and Dynamics, Science 323(5922) (2009) 1705-1708.

[55] N.R. Nirala, G. Khandelwal, B. Kumar, Vinita, R. Prakash, V. Kumar, One step electrooxidative preparation of graphene quantum dots from wood charcoal as a peroxidase mimetic, Talanta 173 (2017) 36-43.

[56] K.A. Ritter, J.W. Lyding, The influence of edge structure on the electronic properties of graphene quantum dots and nanoribbons, Nat. Mater. 8(3) (2009) 235-242.

[57] K.S. Novoselov, A.K. Geim, S.V. Morozov, D. Jiang, Y. Zhang, S.V. Dubonos, I.V. Grigorieva, A.A. Firsov, Electric Field Effect in Atomically Thin Carbon Films, Science 306(5696) (2004) 666-669.

[58] D. Pan, J. Zhang, Z. Li, M. Wu, Hydrothermal route for cutting graphene sheets into blueluminescent graphene quantum dots, Adv. Mater. 22(6) (2010) 734-738.

[59] J. Peng, W. Gao, B.K. Gupta, Z. Liu, R. Romero-Aburto, L. Ge, L. Song, L.B. Alemany, X. Zhan, G. Gao, S.A. Vithayathil, B.A. Kaipparettu, A.A. Marti, T. Hayashi, J.-J. Zhu, P.M. Ajayan, Graphene Quantum Dots Derived from Carbon Fibers, Nano Lett. 12(2) (2012) 844849.

[60] L.A. Ponomarenko, F. Schedin, M.I. Katsnelson, R. Yang, E.W. Hill, K.S. Novoselov, A.K. Geim, Chaotic Dirac Billiard in Graphene Quantum Dots, Science 320(5874) (2008) 356358. 
[61] M.-H. Jang, S.H. Song, H.D. Ha, T.S. Seo, S. Jeon, Y.-H. Cho, Origin of extraordinary luminescence shift in graphene quantum dots with varying excitation energy: An experimental evidence of localized sp2 carbon subdomain, Carbon 118 (2017) 524-530.

[62] X. Wang, G. Sun, N. Li, P. Chen, Quantum dots derived from two-dimensional materials and their applications for catalysis and energy, Chem. Soc. Rev. 45(8) (2016) 2239-2262.

[63] M. Shamsipur, A. Barati, S. Karami, Long-wavelength, multicolor, and white-light emitting carbon-based dots: Achievements made, challenges remaining, and applications, Carbon 124 (2017) 429-472.

[64] V. Georgakilas, J.A. Perman, J. Tucek, R. Zboril, Broad Family of Carbon Nanoallotropes: Classification, Chemistry, and Applications of Fullerenes, Carbon Dots, Nanotubes, Graphene, Nanodiamonds, and Combined Superstructures, Chem. Rev. 115(11) (2015) 4744-4822.

[65] C.S. Lim, K. Hola, A. Ambrosi, R. Zboril, M. Pumera, Graphene and carbon quantum dots electrochemistry, Electrochem. Commun. 52 (2015) 75-79.

[66] S.N. Baker, G.A. Baker, Luminescent carbon nanodots: emergent nanolights, Angew. Chem. Int. Ed. 49(38) (2010) 6726-6744.

[67] H. Peng, J. Travas-Sejdic, Simple Aqueous Solution Route to Luminescent Carbogenic Dots from Carbohydrates, Chem. Mater. 21(23) (2009) 5563-5565.

[68] Z. Zhang, J. Zhang, N. Chen, L. Qu, Graphene quantum dots: an emerging material for energy-related applications and beyond, Energy Environ. Sci. 5(10) (2012) 8869-8890.

[69] K. Li, X. Zhao, G. Wei, Z. Su, Recent Advance in the Cancer Bioimaging with Graphene Quantum Dots, Curr. Med. Chem. (2017).

[70] L. Feng, Y.-X. Wu, D.-L. Zhang, X. Hu, J. Zhang, P. Wang, Z.-L. Song, X.-B. Zhang, W. Tan, A Near Infrared Graphene Quantum Dots-Based Two-Photon Nanoprobe for Direct Bioimaging of Endogenous Ascorbic Acid in Living Cells, Anal. Chem. (2017).

[71] A. Ananthanarayanan, Y. Wang, P. Routh, M.A. Sk, A. Than, M. Lin, J. Zhang, J. Chen, H. Sun, P. Chen, Nitrogen and phosphorus co-doped graphene quantum dots: synthesis from adenosine triphosphate, optical properties, and cellular imaging, Nanoscale 7(17) (2015) 81598165.

[72] P. Roy, A.P. Periasamy, C. Chuang, Y.-R. Liou, Y.-F. Chen, J. Joly, C.-T. Liang, H.-T. Chang, Plant leaf-derived graphene quantum dots and applications for white LEDs, New J. Chem. 38(10) (2014) 4946-4951.

[73] Z. Wang, J. Yu, X. Zhang, N. Li, B. Liu, Y. Li, Y. Wang, W. Wang, Y. Li, L. Zhang, Large-scale and controllable synthesis of graphene quantum dots from rice husk biomass: a comprehensive utilization strategy, ACS Appl. Mater. Interfaces 8(2) (2016) 1434-1439.

[74] A. Suryawanshi, M. Biswal, D. Mhamane, R. Gokhale, S. Patil, D. Guin, S. Ogale, Large scale synthesis of graphene quantum dots (GQDs) from waste biomass and their use as an efficient and selective photoluminescence on-off-on probe for Ag+ ions, Nanoscale 6(20) (2014) 11664-11670.

[75] L. Wang, W. Li, B. Wu, Z. Li, S. Wang, Y. Liu, D. Pan, M. Wu, Facile synthesis of fluorescent graphene quantum dots from coffee grounds for bioimaging and sensing, Chem. Eng. J. 300 (2016) 75-82.

[76] M. Biswal, A. Banerjee, M. Deo, S. Ogale, From dead leaves to high energy density supercapacitors, Energy Environ. Sci. 6(4) (2013) 1249-1259.

[77] J. Peng, W. Gao, B.K. Gupta, Z. Liu, R. Romero-Aburto, L. Ge, L. Song, L.B. Alemany, X. Zhan, G. Gao, Graphene quantum dots derived from carbon fibers, Nano Lett. 12(2) (2012) 844-849.

[78] S. Yang, J. Sun, X. Li, W. Zhou, Z. Wang, P. He, G. Ding, X. Xie, Z. Kang, M. Jiang, Large-scale fabrication of heavy doped carbon quantum dots with tunable-photoluminescence and sensitive fluorescence detection, J. Mater. Chem. A 2(23) (2014) 8660-8667. 
[79] S. Yang, Y. Yang, P. He, G. Wang, G. Ding, X. Xie, Insights into the Oxidation Mechanism of sp2-sp3 Hybrid Carbon Materials: Preparation of a Water-Soluble 2D Porous Conductive Network and Detectable Molecule Separation, Langmuir 33(4) (2017) 913-919.

[80] C. Zhu, S. Yang, G. Wang, R. Mo, P. He, J. Sun, Z. Di, Z. Kang, N. Yuan, J. Ding, A new mild, clean and highly efficient method for the preparation of graphene quantum dots without by-products, J. Mater. Chem. B 3(34) (2015) 6871-6876.

[81] X. Zhou, Y. Zhang, C. Wang, X. Wu, Y. Yang, B. Zheng, H. Wu, S. Guo, J. Zhang, PhotoFenton reaction of graphene oxide: a new strategy to prepare graphene quantum dots for DNA cleavage, ACS Nano 6(8) (2012) 6592-6599.

[82] L. Li, G. Wu, G. Yang, J. Peng, J. Zhao, J.-J. Zhu, Focusing on luminescent graphene quantum dots: current status and future perspectives, Nanoscale 5(10) (2013) 4015-4039.

[83] A. Ananthanarayanan, X. Wang, P. Routh, B. Sana, S. Lim, D.H. Kim, K.H. Lim, J. Li, P. Chen, Facile synthesis of graphene quantum dots from 3D graphene and their application for Fe3+ sensing, Adv. Funct. Mater. 24(20) (2014) 3021-3026.

[84] Y. Dong, C. Chen, X. Zheng, L. Gao, Z. Cui, H. Yang, C. Guo, Y. Chi, C.M. Li, One-step and high yield simultaneous preparation of single-and multi-layer graphene quantum dots from CX-72 carbon black, J. Mater. Chem. 22(18) (2012) 8764-8766.

[85] H. Park, S.H. Noh, J.H. Lee, W.J. Lee, J.Y. Jaung, S.G. Lee, T.H. Han, Large scale synthesis and light emitting fibers of tailor-made graphene quantum dots, Sci. Rep. 5 (2015) 14163.

[86] L. Wang, X. Chen, Y. Lu, C. Liu, W. Yang, Carbon quantum dots displaying dualwavelength photoluminescence and electrochemiluminescence prepared by high-energy ball milling, Carbon 94 (2015) 472-478.

[87] S. Zhuo, M. Shao, S.-T. Lee, Upconversion and downconversion fluorescent graphene quantum dots: ultrasonic preparation and photocatalysis, ACS Nano 6(2) (2012) 1059-1064.

[88] J. Lu, J.-x. Yang, J. Wang, A. Lim, S. Wang, K.P. Loh, One-pot synthesis of fluorescent carbon nanoribbons, nanoparticles, and graphene by the exfoliation of graphite in ionic liquids, ACS Nano 3(8) (2009) 2367-2375.

[89] Q. Li, S. Zhang, L. Dai, L.-s. Li, Nitrogen-doped colloidal graphene quantum dots and their size-dependent electrocatalytic activity for the oxygen reduction reaction, J. Am. Chem. Soc. 134(46) (2012) 18932-18935.

[90] Y. Li, Y. Hu, Y. Zhao, G. Shi, L. Deng, Y. Hou, L. Qu, An electrochemical avenue to green-luminescent graphene quantum dots as potential electron-acceptors for photovoltaics, Adv. Mater. 23(6) (2011) 776-780.

[91] H. Li, X. He, Z. Kang, H. Huang, Y. Liu, J. Liu, S. Lian, C.H.A. Tsang, X. Yang, S.T. Lee, Water-soluble fluorescent carbon quantum dots and photocatalyst design, Angew. Chem. 122(26) (2010) 4532-4536.

[92] Y. Li, Y. Zhao, H. Cheng, Y. Hu, G. Shi, L. Dai, L. Qu, Nitrogen-doped graphene quantum dots with oxygen-rich functional groups, J. Am. Chem. Soc. 134(1) (2011) 15-18.

[93] J. Sun, S. Yang, Z. Wang, H. Shen, T. Xu, L. Sun, H. Li, W. Chen, X. Jiang, G. Ding, Ultra-High Quantum Yield of Graphene Quantum Dots: Aromatic-Nitrogen Doping and Photoluminescence Mechanism, Part. Part. Syst. Char. 32(4) (2015) 434-440.

[94] X. Yan, X. Cui, B. Li, L.-s. Li, Large, solution-processable graphene quantum dots as light absorbers for photovoltaics, Nano Lett. 10(5) (2010) 1869-1873.

[95] L. Wang, Y. Wang, T. Xu, H. Liao, C. Yao, Y. Liu, Z. Li, Z. Chen, D. Pan, L. Sun, Gramscale synthesis of single-crystalline graphene quantum dots with superior optical properties, Nat. Commun. 5 (2014).

[96] A.B. Bourlinos, A. Stassinopoulos, D. Anglos, R. Zboril, M. Karakassides, E.P. Giannelis, Surface functionalized carbogenic quantum dots, Small 4(4) (2008) 455-458. 
[97] Y. Deng, D. Zhao, X. Chen, F. Wang, H. Song, D. Shen, Long lifetime pure organic phosphorescence based on water soluble carbon dots, Chem. Commun. 49(51) (2013) 57515753.

[98] P.-C. Hsu, Z.-Y. Shih, C.-H. Lee, H.-T. Chang, Synthesis and analytical applications of photoluminescent carbon nanodots, Green Chem. 14(4) (2012) 917-920.

[99] Y. Dong, J. Shao, C. Chen, H. Li, R. Wang, Y. Chi, X. Lin, G. Chen, Blue luminescent graphene quantum dots and graphene oxide prepared by tuning the carbonization degree of citric acid, Carbon 50(12) (2012) 4738-4743.

[100] S. Wang, Z.-G. Chen, I. Cole, Q. Li, Structural evolution of graphene quantum dots during thermal decomposition of citric acid and the corresponding photoluminescence, Carbon 82 (2015) 304-313.

[101] X. Jia, J. Li, E. Wang, One-pot green synthesis of optically pH-sensitive carbon dots with upconversion luminescence, Nanoscale 4(18) (2012) 5572-5575.

[102] C.-W. Lai, Y.-H. Hsiao, Y.-K. Peng, P.-T. Chou, Facile synthesis of highly emissive carbon dots from pyrolysis of glycerol; gram scale production of carbon dots/mSiO 2 for cell imaging and drug release, J. Mater. Chem. 22(29) (2012) 14403-14409.

[103] H. Kalita, J. Mohapatra, L. Pradhan, A. Mitra, D. Bahadur, M. Aslam, Efficient synthesis of rice based graphene quantum dots and their fluorescent properties, RSC Adv. 6(28) (2016) 23518-23524.

[104] S. Mahesh, C.L. Lekshmi, K.D. Renuka, K. Joseph, Simple and Cost-Effective Synthesis of Fluorescent Graphene Quantum Dots from Honey: Application as Stable Security Ink and White-Light Emission, Part. Part. Syst. Char. 33(2) (2016) 70-74.

[105] D. Qu, M. Zheng, L. Zhang, H. Zhao, Z. Xie, X. Jing, R.E. Haddad, H. Fan, Z. Sun, Formation mechanism and optimization of highly luminescent N-doped graphene quantum dots, Sci. Rep. 4 (2014) 5294.

[106] X. Li, S.P. Lau, L. Tang, R. Ji, P. Yang, Sulphur doping: a facile approach to tune the electronic structure and optical properties of graphene quantum dots, Nanoscale 6(10) (2014) 5323-5328.

[107] G. Wang, Q. Guo, D. Chen, Z. Liu, X. Zheng, A. Xu, S. Yang, G. Ding, Facile and highly effective synthesis of controllable lattice sulfur-doped graphene quantum dots via hydrothermal treatment of durian, ACS Appl. Mater. Interfaces (2018).

[108] S. Yang, W. Li, C. Ye, G. Wang, H. Tian, C. Zhu, P. He, G. Ding, X. Xie, Y. Liu, C3NA 2D Crystalline, Hole-Free, Tunable-Narrow-Bandgap Semiconductor with Ferromagnetic Properties, Adv. Mater. 29(16) (2017).

[109] M.A. Sk, A. Ananthanarayanan, L. Huang, K.H. Lim, P. Chen, Revealing the tunable photoluminescence properties of graphene quantum dots, J. Mater. Chem. C 2(34) (2014) 6954-6960.

[110] N. Mohanty, D. Moore, Z. Xu, T.S. Sreeprasad, A. Nagaraja, A.A. Rodriguez, V. Berry, Nanotomy-based production of transferable and dispersible graphene nanostructures of controlled shape and size, Nat. Commun. 3 (2012) 844.

[111] X. Yan, X. Cui, L.-s. Li, Synthesis of large, stable colloidal graphene quantum dots with tunable size, J. Am. Chem. Soc. 132(17) (2010) 5944-5945.

[112] J. Lu, P.S.E. Yeo, C.K. Gan, P. Wu, K.P. Loh, Transforming C60 molecules into graphene quantum dots, Nat. Nanotechnol. 6(4) (2011) 247-252.

[113] A.-X. Zheng, Z.-X. Cong, J.-R. Wang, J. Li, H.-H. Yang, G.-N. Chen, Highly-efficient peroxidase-like catalytic activity of graphene dots for biosensing, Biosens. Bioelectron. 49 (2013) 519-524.

[114] R. Sekiya, Y. Uemura, H. Naito, K. Naka, T. Haino, Chemical Functionalisation and Photoluminescence of Graphene Quantum Dots, Chem. - Eur. J. 22(24) (2016) 8198-8206. 
[115] S. Hu, R. Tian, L. Wu, Q. Zhao, J. Yang, J. Liu, S. Cao, Chemical regulation of carbon quantum dots from synthesis to photocatalytic activity, Chem. - Asian J. 8(5) (2013) 10351041.

[116] S. Zhu, J. Zhang, S. Tang, C. Qiao, L. Wang, H. Wang, X. Liu, B. Li, Y. Li, W. Yu, Surface chemistry routes to modulate the photoluminescence of graphene quantum dots: From fluorescence mechanism to up-conversion bioimaging applications, Adv. Funct. Mater. 22(22) (2012) 4732-4740.

[117] H. Sun, L. Wu, N. Gao, J. Ren, X. Qu, Improvement of photoluminescence of graphene quantum dots with a biocompatible photochemical reduction pathway and its bioimaging application, ACS Appl. Mater. Interfaces 5(3) (2013) 1174-1179.

[118] L.L. Li, J. Ji, R. Fei, C.Z. Wang, Q. Lu, J.R. Zhang, L.P. Jiang, J.J. Zhu, A facile microwave avenue to electrochemiluminescent two-color graphene quantum dots, Adv. Funct. Mater. 22(14) (2012) 2971-2979.

[119] J. Shen, Y. Zhu, C. Chen, X. Yang, C. Li, Facile preparation and upconversion luminescence of graphene quantum dots, Chem. Commun. 47(9) (2011) 2580-2582.

[120] J. Shen, Y. Zhu, X. Yang, J. Zong, J. Zhang, C. Li, One-pot hydrothermal synthesis of graphene quantum dots surface-passivated by polyethylene glycol and their photoelectric conversion under near-infrared light, New J. Chem. 36(1) (2012) 97-101.

[121] Z. Wang, J. Xia, C. Zhou, B. Via, Y. Xia, F. Zhang, Y. Li, L. Xia, J. Tang, Synthesis of strongly green-photoluminescent graphene quantum dots for drug carrier, Colloids Surf., B 112 (2013) 192-196.

[122] M. Zhang, L. Bai, W. Shang, W. Xie, H. Ma, Y. Fu, D. Fang, H. Sun, L. Fan, M. Han, Facile synthesis of water-soluble, highly fluorescent graphene quantum dots as a robust biological label for stem cells, J. Mater. Chem. 22(15) (2012) 7461-7467.

[123] H. Tetsuka, R. Asahi, A. Nagoya, K. Okamoto, I. Tajima, R. Ohta, A. Okamoto, Optically tunable amino-functionalized graphene quantum dots, Adv. Mater. 24(39) (2012) 5333-5338. [124] X. Wang, G. Sun, P. Routh, D.-H. Kim, W. Huang, P. Chen, Heteroatom-doped graphene materials: syntheses, properties and applications, Chem. Soc. Rev. 43(20) (2014) 7067-7098.

[125] J. Ju, W. Chen, Synthesis of highly fluorescent nitrogen-doped graphene quantum dots for sensitive, label-free detection of Fe (III) in aqueous media, Biosens. Bioelectron. 58 (2014) 219-225.

[126] C. Hu, Y. Liu, Y. Yang, J. Cui, Z. Huang, Y. Wang, L. Yang, H. Wang, Y. Xiao, J. Rong, One-step preparation of nitrogen-doped graphene quantum dots from oxidized debris of graphene oxide, J. Mater. Chem. B 1(1) (2013) 39-42.

[127] K.S. Prasad, R. Pallela, D.M. Kim, Y.B. Shim, Microwave-Assisted One-Pot Synthesis of Metal-Free Nitrogen and Phosphorus Dual-Doped Nanocarbon for Electrocatalysis and Cell Imaging, Part. Part. Syst. Char. 30(6) (2013) 557-564.

[128] Z. Qian, X. Shan, L. Chai, J. Ma, J. Chen, H. Feng, Si-doped carbon quantum dots: a facile and general preparation strategy, bioimaging application, and multifunctional sensor, ACS Appl. Mater. Interfaces 6(9) (2014) 6797-6805.

[129] L. Zhang, Z.-Y. Zhang, R.-P. Liang, Y.-H. Li, J.-D. Qiu, Boron-doped graphene quantum dots for selective glucose sensing based on the "abnormal" aggregation-induced photoluminescence enhancement, Anal. Chem. 86(9) (2014) 4423-4430.

[130] D. Qu, M. Zheng, P. Du, Y. Zhou, L. Zhang, D. Li, H. Tan, Z. Zhao, Z. Xie, Z. Sun, Highly luminescent $S$, N co-doped graphene quantum dots with broad visible absorption bands for visible light photocatalysts, Nanoscale 5(24) (2013) 12272-12277.

[131] S. Guo, S. Dong, Graphene nanosheet: synthesis, molecular engineering, thin film, hybrids, and energy and analytical applications, Chem. Soc. Rev. 40(5) (2011) 2644-2672. 
[132] V. Georgakilas, J.N. Tiwari, K.C. Kemp, J.A. Perman, A.B. Bourlinos, K.S. Kim, R. Zboril, Noncovalent Functionalization of Graphene and Graphene Oxide for Energy Materials, Biosensing, Catalytic, and Biomedical Applications, Chem. Rev. 116(9) (2016) 5464-5519.

[133] C. Xu, B. Xu, Y. Gu, Z. Xiong, J. Sun, X.S. Zhao, Graphene-based electrodes for electrochemical energy storage, Energy Environ. Sci. 6(6) (2013) 1388-1414.

[134] Y. Sun, Q. Wu, G. Shi, Graphene based new energy materials, Energy Environ. Sci. 4(4) (2011) 1113-1132.

[135] S. Mao, G. Lu, J. Chen, Three-dimensional graphene-based composites for energy applications, Nanoscale 7(16) (2015) 6924-6943.

[136] C. Hu, L. Song, Z. Zhang, N. Chen, Z. Feng, L. Qu, Tailored graphene systems for unconventional applications in energy conversion and storage devices, Energy Environ. Sci. 8(1) (2015) 31-54.

[137] X. Rui, J. Zhu, D. Sim, C. Xu, Y. Zeng, H.H. Hng, T.M. Lim, Q. Yan, Reduced graphene oxide supported highly porous $\mathrm{V} 2 \mathrm{O} 5$ spheres as a high-power cathode material for lithium ion batteries, Nanoscale 3(11) (2011) 4752-4758.

[138] D. Wang, L. Wang, X. Dong, Z. Shi, J. Jin, Chemically tailoring graphene oxides into fluorescent nanosheets for Fe3+ ion detection, Carbon 50(6) (2012) 2147-2154.

[139] Y. Dong, G. Li, N. Zhou, R. Wang, Y. Chi, G. Chen, Graphene Quantum Dot as a Green and Facile Sensor for Free Chlorine in Drinking Water, Anal. Chem. 84(19) (2012) 8378-8382.

[140] J.-M. Bai, L. Zhang, R.-P. Liang, J.-D. Qiu, Graphene Quantum Dots Combined with Europium Ions as Photoluminescent Probes for Phosphate Sensing, Chemistry - A European Journal 19(12) (2013) 3822-3826.

[141] J.K. Kim, S.J. Kim, M.J. Park, S. Bae, S.-P. Cho, Q.G. Du, D.H. Wang, J.H. Park, B.H. Hong, Surface-engineered graphene quantum dots incorporated into polymer layers for high performance organic photovoltaics, Sci. Rep. 5 (2015).

[142] S.H. Song, M.H. Jang, J. Chung, S.H. Jin, B.H. Kim, S.H. Hur, S. Yoo, Y.H. Cho, S. Jeon, Highly Efficient Light-Emitting Diode of Graphene Quantum Dots Fabricated from Graphite Intercalation Compounds, Adv. Opt. Mater. 2(11) (2014) 1016-1023.

[143] L. Tang, R. Ji, X. Cao, J. Lin, H. Jiang, X. Li, K.S. Teng, C.M. Luk, S. Zeng, J. Hao, Deep ultraviolet photoluminescence of water-soluble self-passivated graphene quantum dots, ACS Nano 6(6) (2012) 5102-5110.

[144] S. Diao, X. Zhang, Z. Shao, K. Ding, J. Jie, X. Zhang, 12.35\% efficient graphene quantum dots/silicon heterojunction solar cells using graphene transparent electrode, Nano Energy 31 (2017) 359-366.

[145] A. Marinovic, L.S. Kiat, S. Dunn, M.M. Titirici, J. Briscoe, Carbon-Nanodot Solar Cells from Renewable Precursors, ChemSusChem 10(5) (2017) 1004-1013.

[146] T. Van Tam, S.G. Kang, F.B. Kadumudi, E. Oh, S.G. Lee, W.M. Choi, Synthesis of Bdoped graphene quantum dots as metal-free electrocatalyst for oxygen reduction reaction, J. Mater. Chem. A (2017).

[147] D. Chao, C. Zhu, X. Xia, J. Liu, X. Zhang, J. Wang, P. Liang, J. Lin, H. Zhang, Z.X. Shen, H.J. Fan, Graphene quantum dots coated VO2 arrays for highly durable electrodes for Li and $\mathrm{Na}$ ion batteries, Nano Lett. 15(1) (2015) 565-573.

[148] J. Park, J. Moon, C. Kim, J.H. Kang, E. Lim, J. Park, K.J. Lee, S.-H. Yu, J.-H. Seo, J. Lee, Graphene quantum dots: structural integrity and oxygen functional groups for high sulfur/sulfide utilization in lithium sulfur batteries, NPG Asia Mater. 8 (2016) e272.

[149] M.S. Islam, Y. Deng, L. Tong, A.K. Roy, S.N. Faisal, M. Hassan, A.I. Minett, V.G. Gomes, In-situ direct grafting of graphene quantum dots onto carbon fibre by low temperature chemical synthesis for high performance flexible fabric supercapacitor, Mater. Today Commun. 10 (2017) 112-119. 
[150] W.W. Liu, Y.Q. Feng, X.B. Yan, J.T. Chen, Q.J. Xue, Superior Micro-Supercapacitors Based on Graphene Quantum Dots, Adv. Funct. Mater. 23(33) (2013) 4111-4122.

[151] S.-H. Choi, Unique properties of graphene quantum dots and their applications in photonic/electronic devices, J. Phys. D: Appl. Phys. 50(10) (2017) 103002.

[152] W. Kwon, Y.-H. Kim, C.-L. Lee, M. Lee, H.C. Choi, T.-W. Lee, S.-W. Rhee, Electroluminescence from graphene quantum dots prepared by amidative cutting of tattered graphite, Nano Lett. 14(3) (2014) 1306-1311.

[153] L. Zhang, D. DeArmond, N.T. Alvarez, R. Malik, N. Oslin, C. McConnell, P.K. Adusei, Y.Y. Hsieh, V. Shanov, Flexible Micro-Supercapacitor Based on Graphene with 3D Structure, Small (2017).

[154] Y. Zhu, S. Murali, M.D. Stoller, K.J. Ganesh, W. Cai, P.J. Ferreira, A. Pirkle, R.M. Wallace, K.A. Cychosz, M. Thommes, Carbon-based supercapacitors produced by activation of graphene, Science 332(6037) (2011) 1537-1541.

[155] S.Z. Butler, S.M. Hollen, L. Cao, Y. Cui, J.A. Gupta, H.R. Gutiérrez, T.F. Heinz, S.S. Hong, J. Huang, A.F. Ismach, Progress, challenges, and opportunities in two-dimensional materials beyond graphene, ACS Nano 7(4) (2013) 2898-2926.

[156] H. Zhang, Ultrathin two-dimensional nanomaterials, ACS Nano 9(10) (2015) 9451-9469.

[157] L.F. Castañeda, F.C. Walsh, J.L. Nava, C.P. de León, Graphite felt as a versatile electrode material: Properties, reaction environment, performance and applications, Electrochim. Acta (2017).

[158] F.C. Walsh, L.F. Arenas, C. Ponce de León, G.W. Reade, I. Whyte, B.G. Mellor, The continued development of reticulated vitreous carbon as a versatile electrode material: Structure, properties and applications, Electrochim. Acta 215 (2016) 566-591.

[159] Y. Hu, Y. Zhao, G. Lu, N. Chen, Z. Zhang, H. Li, H. Shao, L. Qu, Graphene quantum dots-carbon nanotube hybrid arrays for supercapacitors, Nanotechnology 24(19) (2013) 195401.

[160] W. Liu, X. Yan, J. Chen, Y. Feng, Q. Xue, Novel and high-performance asymmetric micro-supercapacitors based on graphene quantum dots and polyaniline nanofibers, Nanoscale 5(13) (2013) 6053-6062.

[161] Q. Chen, Y. Hu, C. Hu, H. Cheng, Z. Zhang, H. Shao, L. Qu, Graphene quantum dotsthree-dimensional graphene composites for high-performance supercapacitors, PCCP 16(36) (2014) 19307-19313.

[162] S. Mondal, U. Rana, S. Malik, Graphene quantum dot-doped polyaniline nanofiber as high performance supercapacitor electrode materials, Chem. Commun. 51(62) (2015) 1236512368.

[163] D.-W. Wang, F. Li, J. Zhao, W. Ren, Z.-G. Chen, J. Tan, Z.-S. Wu, I. Gentle, G.Q. Lu, H.-M. Cheng, Fabrication of graphene/polyaniline composite paper via in situ anodic electropolymerization for high-performance flexible electrode, ACS Nano 3(7) (2009) 17451752.

[164] D. Yu, K. Goh, H. Wang, L. Wei, W. Jiang, Q. Zhang, L. Dai, Y. Chen, Scalable synthesis of hierarchically structured carbon nanotube-graphene fibres for capacitive energy storage, Nat. Nanotechnol. 9(7) (2014) 555-562.

[165] L. Kou, T. Huang, B. Zheng, Y. Han, X. Zhao, K. Gopalsamy, H. Sun, C. Gao, Coaxial wet-spun yarn supercapacitors for high-energy density and safe wearable electronics, Nat. Commun. 5 (2014).

[166] H. Cheng, C. Hu, Y. Zhao, L. Qu, Graphene fiber: a new material platform for unique applications, NPG Asia Mater. 6(7) (2014) e113.

[167] M. Hassan, E. Haque, K.R. Reddy, A.I. Minett, J. Chen, V.G. Gomes, Edge-enriched graphene quantum dots for enhanced photo-luminescence and supercapacitance, Nanoscale 6(20) (2014) 11988-11994. 
[168] C. Zhu, D. Chao, J. Sun, I.M. Bacho, Z. Fan, C.F. Ng, X. Xia, H. Huang, H. Zhang, Z.X. Shen, G. Ding, H.J. Fan, Enhanced lithium storage performance of $\mathrm{CuO}$ nanowires by coating of graphene quantum dots, Adv. Mater. Interfaces 2(2) (2015) 1400499.

[169] K. Lijuan, Y. Yongqiang, L. Ruiyi, L. Zaijun, Phenylalanine-functionalized graphene quantum dot-silicon nanoparticle composite as an anode material for lithium ion batteries with largely enhanced electrochemical performance, Electrochim. Acta 198 (2016) 144-155.

[170] L. Ruiyi, J. Yuanyuan, Z. Xiaoyan, L. Zaijun, G. Zhiguo, W. Guangli, L. Junkang, Significantly enhanced electrochemical performance of lithium titanate anode for lithium ion battery by the hybrid of nitrogen and sulfur co-doped graphene quantum dots, Electrochim. Acta 178 (2015) 303-311.

[171] M. Wang, Z. Fang, K. Zhang, J. Fang, F. Qin, Z. Zhang, J. Li, Y. Liu, Y. Lai, Synergistically enhanced activity of graphene quantum dots/graphene hydrogel composites: a novel all-carbon hybrid electrocatalyst for metal/air batteries, Nanoscale 8(22) (2016) 1139811402.

[172] J. Ren, Y. Zhang, W. Bai, X. Chen, Z. Zhang, X. Fang, W. Weng, Y. Wang, H. Peng, Elastic and wearable wire-shaped lithium-ion battery with high electrochemical performance, Angew. Chem. 126(30) (2014) 7998-8003.

[173] M. Ye, Z. Dong, C. Hu, H. Cheng, H. Shao, N. Chen, L. Qu, Uniquely Arranged Graphene-on-Graphene Structure as a Binder-Free Anode for High-Performance Lithium-Ion Batteries, Small 10(24) (2014) 5035-5041.

[174] D. Wang, R. Kou, D. Choi, Z. Yang, Z. Nie, J. Li, L.V. Saraf, D. Hu, J. Zhang, G.L. Graff, Ternary self-assembly of ordered metal oxide- graphene nanocomposites for electrochemical energy storage, ACS Nano 4(3) (2010) 1587-1595.

[175] P. Gao, K. Ding, Y. Wang, K. Ruan, S. Diao, Q. Zhang, B. Sun, J. Jie, Crystalline Si/graphene quantum dots heterojunction solar cells, J. Phys. Chem. C 118(10) (2014) 51645171.

[176] M. Dutta, S. Sarkar, T. Ghosh, D. Basak, ZnO/graphene quantum dot solid-state solar cell, J. Phys. Chem. C 116(38) (2012) 20127-20131.

[177] M.M. Tavakoli, H. Aashuri, A. Simchi, S. Kalytchuk, Z. Fan, Quasi core/shell lead sulfide/graphene quantum dots for bulk heterojunction solar cells, J. Phys. Chem. C 119(33) (2015) 18886-18895.

[178] J. Zhao, L. Tang, J. Xiang, R. Ji, Y. Hu, J. Yuan, J. Zhao, Y. Tai, Y. Cai, Fabrication and properties of a high-performance chlorine doped graphene quantum dot based photovoltaic detector, RSC Adv. 5(37) (2015) 29222-29229.

[179] Z. Zhu, J. Ma, Z. Wang, C. Mu, Z. Fan, L. Du, Y. Bai, L. Fan, H. Yan, D.L. Phillips, Efficiency enhancement of perovskite solar cells through fast electron extraction: the role of graphene quantum dots, J. Am. Chem. Soc. 136(10) (2014) 3760-3763.

[180] V. Gupta, N. Chaudhary, R. Srivastava, G.D. Sharma, R. Bhardwaj, S. Chand, Luminscent graphene quantum dots for organic photovoltaic devices, J. Am. Chem. Soc. 133(26) (2011) 9960-9963.

[181] J.K. Kim, M.J. Park, S.J. Kim, D.H. Wang, S.P. Cho, S. Bae, J.H. Park, B.H. Hong, Balancing light absorptivity and carrier conductivity of graphene quantum dots for highefficiency bulk heterojunction solar cells, ACS Nano 7(8) (2013) 7207-7212.

[182] R. Long, Understanding the Electronic Structures of Graphene Quantum Dot Physisorption and Chemisorption onto the TiO2 (110) Surface: A First-Principles Calculation, ChemPhysChem 14(3) (2013) 579-582.

[183] K.J. Williams, C.A. Nelson, X. Yan, L.-S. Li, X. Zhu, Hot electron injection from graphene quantum dots to TiO2, ACS Nano 7(2) (2013) 1388-1394.

[184] X. Fang, M. Li, K. Guo, J. Li, M. Pan, L. Bai, M. Luoshan, X. Zhao, Graphene quantum dots optimization of dye-sensitized solar cells, Electrochim. Acta 137 (2014) 634-638. 
[185] I. Mihalache, A. Radoi, M. Mihaila, C. Munteanu, A. Marin, M. Danila, M. Kusko, C. Kusko, Charge and energy transfer interplay in hybrid sensitized solar cells mediated by graphene quantum dots, Electrochim. Acta 153 (2015) 306-315.

[186] E. Lee, J. Ryu, J. Jang, Fabrication of graphene quantum dots via size-selective precipitation and their application in upconversion-based DSSCs, Chem. Commun. 49(85) (2013) 9995-9997.

[187] L. Chen, C.X. Guo, Q. Zhang, Y. Lei, J. Xie, S. Ee, G. Guai, Q. Song, C.M. Li, Graphene quantum-dot-doped polypyrrole counter electrode for high-performance dye-sensitized solar cells, ACS Appl. Mater. Interfaces 5(6) (2013) 2047-2052.

[188] M.L. Mueller, X. Yan, B. Dragnea, L.-s. Li, Slow hot-carrier relaxation in colloidal graphene quantum dots, Nano Lett. 11(1) (2010) 56-60.

[189] M.L. Mueller, X. Yan, J.A. McGuire, L.-s. Li, Triplet states and electronic relaxation in photoexcited graphene quantum dots, Nano Lett. 10(7) (2010) 2679-2682.

[190] Z. Yang, H. Sun, T. Chen, L. Qiu, Y. Luo, H. Peng, Photovoltaic wire derived from a graphene composite fiber achieving an $8.45 \%$ energy conversion efficiency, Angew. Chem. 125(29) (2013) 7693-7696.

[191] C.X. Guo, H.B. Yang, Z.M. Sheng, Z.S. Lu, Q.L. Song, C.M. Li, Layered graphene/quantum dots for photovoltaic devices, Angew. Chem. Int. Ed. 49(17) (2010) 30143017.

[192] H. Sun, X. You, J. Deng, X. Chen, Z. Yang, J. Ren, H. Peng, Novel graphene/carbon nanotube composite fibers for efficient wire-shaped miniature energy devices, Adv. Mater. 26(18) (2014) 2868-2873.

[193] J. Dai, X.C. Zeng, Bilayer phosphorene: effect of stacking order on bandgap and its potential applications in thin-film solar cells, J. Phys. Chem. Lett. 5(7) (2014) 1289-1293.

[194] Y. Deng, Z. Luo, N.J. Conrad, H. Liu, Y. Gong, S. Najmaei, P.M. Ajayan, J. Lou, X. Xu, P.D. Ye, Black phosphorus-monolayer MoS2 van der Waals heterojunction p-n diode, ACS Nano 8(8) (2014) 8292-8299.

[195] M. Buscema, D.J. Groenendijk, G.A. Steele, H.S. Van Der Zant, A. Castellanos-Gomez, Photovoltaic effect in few-layer black phosphorus PN junctions defined by local electrostatic gating, arXiv preprint arXiv:1407.2863 (2014).

[196] G. He, Y. Song, K. Liu, A. Walter, S. Chen, S. Chen, Oxygen reduction catalyzed by platinum nanoparticles supported on graphene quantum dots, ACS Catal. 3(5) (2013) 831-838. [197] M.K. Kumawat, R. Srivastava, M. Thakur, R.B. Gurung, Graphene quantum dots from mangifera indica: Application in near-infrared bioimaging and intracellular nanothermometry, ACS Sustainable Chemistry and Engineering 5(2) (2017) 1382-1391.

[198] J. Lin, X. Chen, P. Huang, Graphene-based nanomaterials for bioimaging, Adv. Drug Delivery Rev. 105 (2016) 242-254.

[199] Y.L. Su, T.W. Yu, W.H. Chiang, H.C. Chiu, C.H. Chang, C.S. Chiang, S.H. Hu, Hierarchically Targeted and Penetrated Delivery of Drugs to Tumors by Size-Changeable Graphene Quantum Dot Nanoaircrafts for Photolytic Therapy, Adv. Funct. Mater. (2017).

[200] G. Hong, S. Diao, A.L. Antaris, H. Dai, Carbon Nanomaterials for Biological Imaging and Nanomedicinal Therapy, Chem. Rev. 115(19) (2015) 10816-10906.

[201] V. Biju, Chemical modifications and bioconjugate reactions of nanomaterials for sensing, imaging, drug delivery and therapy, Chem. Soc. Rev. 43(3) (2014) 744-764.

[202] X. Wang, X. Sun, J. Lao, H. He, T. Cheng, M. Wang, S. Wang, F. Huang, Multifunctional graphene quantum dots for simultaneous targeted cellular imaging and drug delivery, Colloids Surf., B 122 (2014) 638-644.

[203] K. Hola, Y. Zhang, Y. Wang, E.P. Giannelis, R. Zboril, A.L. Rogach, Carbon dots Emerging light emitters for bioimaging, cancer therapy and optoelectronics, Nano Today 9(5) (2014) 590-603. 
[204] J. Ge, M. Lan, B. Zhou, W. Liu, L. Guo, H. Wang, Q. Jia, G. Niu, X. Huang, H. Zhou, X. Meng, P. Wang, C.S. Lee, W. Zhang, X. Han, A graphene quantum dot photodynamic therapy agent with high singlet oxygen generation, Nat. Commun. 5 (2014).

[205] X. Yao, X. Niu, K. Ma, P. Huang, J. Grothe, S. Kaskel, Y. Zhu, Graphene Quantum DotsCapped Magnetic Mesoporous Silica Nanoparticles as a Multifunctional Platform for Controlled Drug Delivery, Magnetic Hyperthermia, and Photothermal Therapy, Small 13(2) (2017).

[206] H. Sun, N. Gao, K. Dong, J. Ren, X. Qu, Graphene quantum dots-band-aids used for wound disinfection, ACS Nano 8(6) (2014) 6202-6210.

[207] S.H. Hu, Y.W. Chen, W.T. Hung, I.W. Chen, S.Y. Chen, Quantum-dot-tagged reduced graphene oxide nanocomposites for bright fluorescence bioimaging and photothermal therapy monitored in situ, Adv. Mater. 24(13) (2012) 1748-1754.

[208] G. Konstantatos, M. Badioli, L. Gaudreau, J. Osmond, M. Bernechea, F.P.G. De Arquer, F. Gatti, F.H.L. Koppens, Hybrid grapheneĝquantum dot phototransistors with ultrahigh gain, Nat. Nanotechnol. 7(6) (2012) 363-368.

[209] X.T. Zheng, A. Than, A. Ananthanaraya, D.-H. Kim, P. Chen, Graphene quantum dots as universal fluorophores and their use in revealing regulated trafficking of insulin receptors in adipocytes, ACS Nano 7(7) (2013) 6278-6286. 